CENTRE for ECONOMIC

$P$ E R F O R M A N C E

CEP Discussion Paper No 849

February 2008

\title{
A Swing-State Theory of Trade Protection in the Electoral College
}

Mirabelle Muûls and Dimitra Petropoulou 


\begin{abstract}
This paper develops an infinite-horizon, political agency model with a continuum of political districts, in which incumbent politicians can improve their re-election probability by attracting swing voters in key states through strategic trade protection. A unique equilibrium is shown to exist where incumbents build a reputation of protectionism through their policy decisions. We show that strategic trade protection is more likely when protectionist swing voters have a lead over free-trade supporters in states with relatively strong electoral competition that represent a larger proportion of Electoral College votes. US data is used to test the hypothesis that industrial concentration in swing and decisive states is an important determinant of trade protection of that industry. The empirical findings provide support for the theory and highlight an important, and previously overlooked, determinant of trade protection in the US Electoral College.
\end{abstract}

Keywords: Political Economy, Elections, Electoral College, Swing States, Trade Policy JEL Classifications: D72, D78, F13, R12

This paper was produced as part of the Centre's Globalisation Programme. The Centre for Economic Performance is financed by the Economic and Social Research Council.

\title{
Acknowledgements
}

We would like to thank the ESRC for their financial support and Steve Redding, Daniel Sturm, Tony Venables, Peter Neary, Alejandro Cunat, Henry Overman, and Gilles Duranton for their invaluable comments. Moreover, we would also like to thank all seminar and conference participants at the London School of Economics, and elsewhere, for their feedback.

Mirabelle Muûls is an Occasional Research Assistant with the Globalisation Programme at the Centre for Economic Performance, London School of Economics. Dimitra Petropoulou is an Associate of the Globalisation Programme at CEP and a Lecturer in Economics at Hertford College, University of Oxford.

Published by

Centre for Economic Performance

London School of Economics and Political Science

Houghton Street

London WC2A 2AE

All rights reserved. No part of this publication may be reproduced, stored in a retrieval system or transmitted in any form or by any means without the prior permission in writing of the publisher nor be issued to the public or circulated in any form other than that in which it is published.

Requests for permission to reproduce any article or part of the Working Paper should be sent to the editor at the above address.

(C) M. Muûls and D. Petropoulou, submitted 2007

ISBN 978-0-85328-242-6 


\section{Introduction}

In this paper we develop a multi-jurisdictional, infinite horizon, elections model characterised by asymmetric information between politicians and voters and an absence of policy commitment with regards to trade policy. The political districts of the model, or states, form an electoral college that elects the president from two candidates from rival parties. The model is used to investigate how the distribution of voters with heterogeneous preferences across swing states gives rise to incentives for strategic trade protection by incumbent politicians who wish to maximise their chance of re-election.

The paper contributes to the literature in three ways. First, the model presented extends the trade policy literature by using a political agency methodology that has never been used to address trade policy issues. The approach examines the electoral incentives for the strategic choice of secondary policy issues in a framework characterised by asymmetric information between politicians and voters regarding politicians' preferences over trade policy and lack of pre-commitment to a particular trade policy prior to election. Electoral incentives can cause political incumbents to alter their policy choice in early years in power in order to influence voter beliefs about the nature of future trade policy. By building a reputation as a protectionist or free-trader, the incumbent attracts swing voters to his platform.

The type of policy modelled in this type of framework is characterised by the inability to tailor it to satisfy the preference of voters at the state level, making it a national policy. Trade policy is thus an excellent candidate for a policy with this feature. Hence, it is the ability to garner electoral college votes nationally that drives results, rather than 'pork-barrel' state level politics. Moreover, it is assumed that the political incumbent has discretion over the selection of trade policy. While this is a reduced form of a more general notion of a cohesive government whose policy decisions are influenced by the desire to retain control of power, it is also the case that over the past few decades there have been periods where the US President was granted trade promotion authority (formerly fast-track authority) to determine trade policy. When granted such authority, the President is able to negotiate trade agreements faster, and while Congress retains power to reject proposed legislation, it has no power of amendment and limited room for debate. While discretion of certain policy instruments is constrained by multilateral agreements, there is still considerable scope for erecting Non-Tariff Barriers, or implementing safeguards, granting relevance to the assumptions of our framework.

Second, we contribute to the political agency literature by developing a tractable multi-jurisdictional framework that extends the single-district political agency framework of recent contributions to the literature by List and Sturm (2006) and Besley and Burgess (2002). We model the electoral system as an electoral college, where electoral votes are attached to political states. This innovation adds a spatial dimension that delivers additional results on how the distribution of single-issue voters across swing states can influence trade policy decisions. The framework delivers three new propositions that relate the 
location of swing voters across swing states to the likelihood that incumbents engage in strategic trade protection.

The third contribution of the paper is that we provide empirical evidence using data for the United States that lends support for the type of mechanisms present in the theoretical model. By augmenting the benchmark empirical specification used by Gawande and Bandyopadhyay (2000) we find evidence in the data to support the theoretical hypothesis that the concentration of a sector across states that are both swing and decisive for election outcomes is a significant determinant of the level of trade protection of that sector. This provides formal support for the claims made in the popular press about the politics behind the recent United States - European Union steel tariffs dispute, "that steel tariffs were introduced for short-term political advantage ... in order to gain votes in key states like West Virginia, Ohio, Pennsylvania and Michigan where the steel industry is a major employer" (The Guardian, November 17th, 2003).

The literature with regards to the role of concentration on endogenous protection is, in general, very different to the framework employed in this paper. The first strand of the literature is the long-standing tradition that addresses the role of concentration for collective action. The effect of geographical concentration on facilitating lobby formation and therefore positively affecting trade policy, was first put forward in Olson (1971). The relationship between the location of industry and import barriers has been debated at length in this literature. The "close group" hypothesis that the concentration of firms allows them to overcome free-rider problems and organise lobbying efficiently is widely accepted and Hansen (1990), among others, provides supporting empirical evidence. This contrasts with the "dispersed group" argument which posits that geographically dispersed industries enjoy broader political representation (depending on the electoral rules) as empirically supported by Pincus (1975), for instance. Busch and Reinhart (1999) explicitly distinguishing between geographical concentration, and 'political concentration', defined as the spread of industry across political districts, in order to reconcile the two hypotheses. Their finding that geographically concentrated but politically dispersed industries in the US are more likely to be protected, suggests that the mechanisms linking location, concentration and protection are more complex than simply those that can be captured through standard measures of concentration. This paper is not related to the collective action literature on concentration, focusing instead on the effects of concentration for electoral outcomes and thus electoral incentives to protect. Our framework suggests concentration might not always matter as such, but rather it is the presence of industrial concentrations in pivotal locations that has an impact on trade protection.

The second strand of the literature stems from the seminal contribution of Grossman and Helpman $(1994,1996)$ on "Protection for Sale" that analyses the effects of campaign contributions for policy decision-making. Mitra (1999) considers endogenous lobby formation in a theoretical extension of the Grossman and Helpman framework. A multitude of papers have followed in this strand to explain the determinants of trade policy and are surveyed in Helpman (1997) and Grossman and Helpman (2002). Recent contributions to the lobbying lit- 
erature for trade include Bombardini (2005) who introduces the decisions of individual firms and hence the role of size distributions within industries in determining protection. The relevance of lobbies has been widely tested, for example by Goldberg and Maggi (1997), Gawande and Bandyopadhyay (2000), Eicher and Osang (2002). While geographical concentration measures have also been included in empirical tests of the lobby model, such as Gawande and Bandyopadhyay (2000), they have not been linked to location in swing states. We augment their specification in the empirical section of this paper to show that political decisions also react to electoral incentives.

The most common electoral approach to the political economy of trade and secondary policy issues is that of median voter models, such as Mayer (1984) and probabilistic voting frameworks such as Yang (1995). These have been used, for example, to explain differences in protectionism based on countries' constitutional set-up (Roelfsema, 2004) or to consider how trade retaliation and liberalisation is affected by the ideological distribution of voters in trading partners (Wiberg, 2005). Our framework is distinct from these approaches since we examine the effects of swing voters in a model of the electoral college without policy commitment. We show that a redistribution of voters between states in the electoral college, holding the population of each voter type constant, can make trade protection more or less likely. Such redistributions have no impact in frameworks in the spirit of Mayer (1984).

Willmann (2005) employs a median voter model to offer an explanation for the empirical relationship between geographical concentration and protection by introducing regional voters who anticipate that their representatives will internalise the costs of protection, once at the national level. The model cannot offer an explanation, however, as to why industries with the same degree of geographical concentration, that are located in different political states, may be systematically awarded different levels of protection.

Finally, a growing political agency literature has more recently addressed the issue of electoral incentives for policy choices in secondary policy issues, such as trade policy or environmental policy, about which smaller groups of voters have very strong views. Recent contributions to this literature include Coate and Morris (1998), Besley and Case (1995), Besley and Burgess (2002) and List and Sturm (2006). Our basic modelling approach is closest to Besley and Burgess (2002) and List and Sturm (2006), while extending to a multi-jurisdictional framework.

The remainder of the paper proceeds as follows. Section 2 develops the theoretical model of the electoral college and discuss the testable empirical implications of the model. The theoretical predictions of the model are tested empirically with US data in section 3 . Section 4 concludes.

\section{The Model}

In this section we develop a multi-jurisdictional, infinite horizon, elections model characterised by asymmetric information between politicians and voters and an 
absence of policy commitment with regards to trade policy. Political incumbents with private preferences over trade policy may have an incentive to build a reputation through the strategic selection of trade policy, in order to swing single-issue voters to their platform in forthcoming elections.

The model contributes to the political agency literature by extending the single-district political agency framework of List and Sturm (2006) and Besley and Burgess (2002) to include a continuum of political districts that form an electoral college. This innovation adds a spatial dimension to the political agency framework that delivers results on how the distribution of single-issue voters across swing states can influence trade policy decisions. Moreover, the model extends the trade policy literature by using a methodology from the political agency literature that has not been used before to examine the strategic incentives for trade policy choice. The empirical implications that arise from the theoretical framework are then tested in section 3.

\subsection{Economic Environment}

Consider a country with a continuum of political districts ${ }^{1}$, or states, $s$, over the interval $[0,1]$, each with a unit mass of voters. These states form an electoral college, through which electoral outcomes are determined. In particular, let each state contribute to the electoral outcome through a single electoral college vote, so the aggregate measure of electoral college votes over the continuum of unit interval is also 1 .

Further suppose that in any presidential election in the infinite-horizon game there are two candidates from rival parties, Democrat $(D)$ and Republican $(R)$, competing for votes. An election may be between two newcomers, or alternatively, between an incumbent politician and a challenger. If a candidate wins a majority of votes in a state, then the electoral college vote of that state is won by that candidate. The election is won by the candidate with the majority of electoral college votes, which corresponds to gaining a majority in a measure of states greater than $\frac{1}{2}$.

Politicians are assumed to face a binding term limit of two periods. After two terms of holding office an incumbent leaves the political arena and a new candidate from within the party competes with the rival candidate in the presidential elections.

\subsubsection{Incumbents Policy Preferences}

During each term of office the incumbent politician must choose the level of public spending, or 'ideology', denoted by $g$, and a secondary policy, such as trade policy for a particular sector, denoted by $r$. Politicians of either party whose personal views are in favour of free trade are referred to as 'free-traders' $(F)$,

\footnotetext{
${ }^{1}$ The assumption of a continuum of political districts allows us to appeal to the law of large number in the calculation of electoral college votes won by each candidate. This facilitates the analysis greatly by making the framework tractable. The role of this assumption is discussed in more detail in section 2.4 .
} 
while those in favour of trade protection are referred to as 'protectionists' $(P)$. Suppose that a randomly selected candidate, of either party, is a protectionist with probability $\pi$. While politicians' preferences over public spending are assumed to be public knowledge, their preferences over $r$ are private. Moreover, electoral candidates are unable to commit to a particular trade policy prior to election.

The level of public spending is assumed to be continuous, or, equivalently, ideology is selected from a continuous spectrum. In contrast, trade policy takes the form of a binary choice, to be made by the incumbent politician, between trade protection $(r=1)$ and free trade $(r=0)$. The trade policy is assumed to have negligible financial impact on government revenue, and so the model abstracts from any possible revenue-raising incentives for trade protection.

Suppose politicians earn an 'ego-rent', $\zeta$, from holding a term in office and receive zero payoff when out of office. In addition, a politician faces a utility cost $c=\left\{c_{L}, c_{H}\right\}$ from deviating from his own preferred trade policy, where $c_{H}>c_{L}$. Let the probability of any politician having a low utility cost be $\operatorname{Pr}\left(c=c_{L}\right)=p$. Cost $c$ can be interpreted as a psychological cost of setting a policy in conflict with personal views. Moreover, let $\beta$ denote the common discount factor, where $\beta$ is assumed to satisfy the following restriction:

$$
c_{H}>\beta \zeta>c_{L}>0
$$

Inequality (1) states that the ego-rent from holding one more term in office lies between the high and low utility costs.

\subsubsection{Voter Preferences}

Voters are assumed to have heterogeneous preferences over the two policy issues. Suppose four types of voters comprise the measure of voters in each state. A voter of type $k$ in state $s$, can be either a Democrat $(D)$, a Republican $(R)$, a free-trader $(F)$, or a protectionist $(P)$. Let $\gamma_{k}^{s}$ denote the proportion of voter type $k$ in the unit measure of voters in state $s$, such that:

$$
\sum_{k} \gamma_{k}^{s}=1, \text { where } k \in\{D, R, F, P\} \text { and } \gamma_{k}^{s} \in[0,1]
$$

The $D$ and $R$ voters are indifferent about the trade policy issue and vote purely on the basis of their preferences over public policy. Politicians' choice of $g$ may also be interpreted as reflecting their ideological position, so $D$ and $R$ voters cast their vote according to their ideological preferences. Even though trade protection, e.g. a tariff, raises the relative domestic price of the protected good, we assume this negative effect is negligible compared to the intensity of their ideological preferences. That is, although a price increase in one good in the consumption basket lowers consumer surplus, it is not a sufficient cost to cause voters to shift their support to another platform. Hence, measure $\gamma_{D}^{s}$ of voters always vote Democrat, while $\gamma_{R}^{s}$ always vote Republican, in any presidential election. 
$P$ and $F$ voters are 'single-issue voters' or 'swing voters' with strong preferences over the secondary policy issue, trade policy. Protectionists may be voters employed in import-competing sectors, whose jobs may be at risk from foreign competition under free trade e.g. Steel industry workers whose employment may be secured through a steel tariff. In contrast, free-traders reflect any voters with strong preferences against trade protection, such as, perhaps, students of economics.

The intensity of swing voters' preferences is assumed to be such that the payoff received from the implementation of their preferred trade policy dominates any ideological considerations. Suppose protectionists receive a payoff of $x>0$ if $r=1$ and 0 otherwise, while supporters of free trade receive $x$ if $r=0$ and 0 otherwise. Swing voters thus vote for the candidate they believe has the highest probability of implementing their preferred policy. Where candidates are perceived to be identical in this respect, swing voters are assumed to cast their vote by flipping a coin.

Note that $r$, referred to as trade policy in this paper, can be interpreted as any secondary policy about which a subset of voters have strong views and which has two key characteristics. The first is that $r$ represents a national policy decision that cannot be tailored to satisfy the preferences of voters at the state level. While some voters may have strong preferences regarding, say, the introduction or abolition of the death penalty, it is possible for a policy decision to be made at the state-level, as is observed in the US. In contrast, a tariff on steel imports, or any other trade policy, can only apply at the national level. Other national policies include immigration policy, foreign policy, participation in a regional trade agreement (e.g. European Union membership), membership in international organisation (e.g. WTO), to mention a few.

The second key characteristic of policy $r$ is that the political incumbent is assumed to have discretion over its selection. Whilst we model the decision-maker as an incumbent politician, the model is consistent with a broader interpretation, where decisions are made by a group of government agents operating as a cohesive entity, whose decisions may be influenced by their desire to perpetuate their control of power.

\subsubsection{Electoral Uncertainty}

Uncertainty in the outcome of the election stems from uncertainty at both the state level and the national level. Each state is assumed to be subject to an idiosyncratic pro- $D$ shock, $\nu^{s}$, that can be interpreted as a shock to voter turnout. Since a vote gained by the $D$ candidate, is also a vote lost by the $R$ candidate, a positive (or negative) $\nu^{s}$ gives the $D$ candidate an advantage (or disadvantage) of $2 \nu^{s}$. For convenience, we redefine $2 \nu^{s}$ as $\varepsilon^{s}$. Assume $\varepsilon^{s}$ is distributed identically and independently according to a symmetric, single-peaked probability density function $h\left(\varepsilon^{s}\right)$, with support $[-\psi, \psi]$, and a continuous cumulative distribution function $H\left(\varepsilon^{s}\right)$. The value of $\psi$ is important to the extent that it affects the degree of uncertainty over the outcome of elections in each state. We assume a sufficiently wide support so that all states are 'swing states'. That is, 
no candidate can be certain of winning a majority in any state, but the probability of each candidate winning a majority can be computed for any state with a distribution of voter types, $\gamma_{k}^{s}$, where $k \in\{D, R, F, P\}$, given the incumbent's policy choice $r$ and the cumulative distribution function $H\left(\varepsilon^{s}\right)$.

In addition to uncertainty at the state level, we introduce aggregate uncertainty ${ }^{2}$ in the form of a 'pro-incumbent shock', $u$, in electoral college votes. In an election between two untested politicians, the shock can be in favour of either. Shock $u$ widens (or narrows) the difference in electoral college votes between candidates by $2 u$. For convenience, we redefine $2 u$ as $\eta$, where $\eta$ is distributed according to a symmetric, single-peaked probability density function, $f(\eta)$ and a continuous cumulative distribution function $F(\eta)$. Again, we assume a sufficiently wide support so that no candidate can secure a majority of electoral college votes. In combination, the state-level and national shocks ensure that no candidate can guarantee to win any state $s$, or the electoral college overall.

In the US, the president is elected indirectly through the Electoral College. Voters vote for state electors who pledge to vote for a particular candidate. These electors cast their electoral vote and the candidate with a majority of electoral votes wins the presidency. In our model, voters are assumed to vote for the candidates directly, while the electoral college system is embodied by the fact that candidates need to win a majority in a majority of states to win the election, rather than a direct majority. The assumptions we make are equivalent to assuming that state-level elections are between two honest electors that have pledged to vote for the $D$ or $R$ candidate, respectively, if elected. A state-level majority won by a $D$ elector corresponds to an electoral college vote won by the $D$ presidential candidate, and similarly for states where the $R$ elector wins a majority. Interpreting our model in this way allows shock $\eta$ to be interpreted as mistakes made by electors when voting, or the presence of a random measure of 'faithless electors' who vote for a candidate other than the candidate pledged. Assuming $f(\eta)$ is symmetric around 0 and single-peaked implies that large measures of mistakes in electoral votes cast or large measures of faithless electors are increasingly unlikely.

\subsubsection{Timing of the Elections Game}

Events in the infinitely repeated elections model with infinitely-lived voters occur in the following order.

1. The incumbent politician draws a period one utility $\operatorname{cost} c=\left\{c_{L}, c_{H}\right\}$, observed only by the incumbent.

2. The incumbent makes policy decisions $g$ and $r$.

3. Policy choices are observed by voters and the election for the presidency in period two takes place.

\footnotetext{
${ }^{2}$ The uncertainty reflected in the state-specific shocks is insufficient to give rise to aggregate uncertainty, as a result of the infinite nature of states along the continuum. We thus introduce aggregate uncertainty in the form of a shock to electoral college votes at the national level. The importance of this assumption is made clear in section 2.4 .
} 
(a) If the term limit is non-binding, then the election is between the incumbent and a randomly selected rival from the other party.

(b) If the term limit is binding, the election is between two randomly selected candidates from either party.

4. The winner of the presidential election is in office in the next period.

The game is then repeated infinitely through stages (1) to (4). In the next few sections we solve the game by backwards induction and characterise the unique equilibrium strategies of voters and politicians, for a given distribution of voters. The strategic incentives for trade policy choice are examined and the role that the distribution of swing voters plays in shaping these incentives is analysed.

\subsection{Political Equilibrium}

The Markov Perfect equilibria of the game between politicians and voters can be characterised by restricting attention to strategies that depend only on payoffrelevant past events, rather than the entire history of the game. Markov strategies for the incumbent politician, $C_{i j}$, where $i \in\{D, R\}$ and $j \in\{F, P\}$ and for type $k^{s}$ voters, where $k^{s} \in\{D, R, F, P\}$, can be said to form an equilibrium if they maximise the value functions of voters and the incumbent politician, given the strategies of the other players.

For the incumbent politician choosing trade policy, the payoff-relevant history of the game is fully described by (a) his utility cost draw, and (b) the number of terms he has already spent in office. Hence, we define a strategy for an incumbent politician as a rule that describes the probability with which he implements trade protection as a function of parameters describing the distribution of voters ${ }^{3}$ across the electoral college, his realised utility cost $c$ and whether he is in his first or second term of office.

For type $k^{s}$ voters, the payoff-relevant history of the game is, where applicable, the first term trade policy decision of an incumbent who is up for reelection against a randomly selected challenger. In elections between two new candidates, there is no payoff-relevant history on which voters can condition their behaviour. For voter types $k^{s}=\{D, R\}$ a strategy is a rule that specifies the probability with which they vote for the Democrat or Republican candidate. For voter types $k^{s}=\{P, F\}$, a strategy is a re-election rule that specifies the probability with which they vote for the incumbent in elections between an incumbent and a challenger, where this probability depends on the updated beliefs regarding the incumbent's private preferences regarding $r$, conditional on the incumbent's trade policy decision in his first term of office.

Let $g^{*}(D)$ and $g^{*}(R)$ be the unique preferred levels of public spending for $D$ and $R$ voters, respectively, where $g^{*}(D)>g^{*}(R)$. It follows directly that $D$ and $R$ candidates always find it optimal to select public spending accordingly ${ }^{4}$ and

\footnotetext{
${ }^{3}$ These are defined fully in the next sections.

${ }^{4}$ For simplicity, we abstract from strategic incentives in public spending
} 
measure $\gamma_{D}^{s}$ of voters always vote Democrat, while $\gamma_{R}^{s}$ always vote Republican, in any presidential election.

The game between incumbents and swing voters ${ }^{5}$ has two symmetric reputationbuilding equilibria, where incumbents choose $r$ strategically in order to swing either $P$ or $F$ voters to their platform. Which of the two applies depends on the distribution of swing voters in the electoral college, as is discussed in more detail in section 2.5. If the incumbent stands to gain from choosing free trade relative to trade protection, then a protectionist incumbent may have an incentive to deviate from his preferred policy choice and choose free trade. The focus of our analysis is the converse case where the distribution of swing voters is such that the Free-trader incumbent may find it optimal to build a reputation as a protectionist. Note that the incentives for Republican and Democrat incumbents are symmetric, since the incentives for trade policy choice hinge on the extent to which free-trader incumbents of either party can improve their re-election probability through trade protection. Since ideology plays no part in the voting decisions of swing voters, the effects are symmetric for $D$ and $R$ incumbents.

The trade policy game is solved by backward induction, starting from the incentives of any politician facing a binding term limit. For any distribution of ideologists and single-issue voters across the electoral college, an incumbent politician in his second term of office has no incentive to choose a trade policy that conflicts with his personal views, since he can never be re-elected. Hence, incumbents always find it optimal to implement their preferred trade policy in their final term of office.

Over the next sections we derive the conditions under which the following strategies constitute an equilibrium of the trade policy game in incumbents' first term of office: free-trader incumbents deviate from their preferred policy and implement trade protection in the first term of office following a low utility cost draw; protectionist incumbents always implement their preferred policy in the first term of office. Furthermore, protectionist voters vote for the incumbent if trade protection has been implemented in the first term of office, and for the challenger otherwise, while free-trader voters vote for the incumbent if trade protection has not been implemented, and for the challenger otherwise. Moreover, this 'reputation-building' equilibrium is unique for distributions ${ }^{6}$ of swing voters under which incumbents can expect to improve their re-election chances through trade protection.

The strategy of a protectionist incumbent is clearly optimal since by implementing trade protection he improves his reelection probability while simultaneously setting his preferred policy. Moreover, if a free-trader incumbent draws a high utility cost $c=c_{H}$, then he always follows his preferred policy choice,

\footnotetext{
${ }^{5}$ The focus of the chapter is the strategic interaction between incumbents and swing voters. For completeness, a discussion of elections between two untested politicians is included in Appendix C.

${ }^{6}$ Appendix B shows this reputation-building equilibrium to be unique for distributions of swing voters where the measure of protectionists versus free-trader voters, and their distribution across the electoral college is such that incumbents stand to gain from implementing trade protection in the first term. A symmetric unique equilibrium exists in the case where incumbents stand to gain through free trade.
} 
since $c_{H}>\beta \zeta$. The benefits in re-election probability can never outweigh the costs of a policy change.

In contrast, a draw of $c_{L}$ may induce a free-trader to set $r=1$ if protectionism sufficiently increases the proportion of electoral college votes won so as to alter the election outcome. Since the incumbent's personal preference over $r$ is hidden from voters, a free trade incumbent in his first term may have an incentive to build a reputation ${ }^{7}$ as a protectionist in order to attract protectionist voters to his platform in the next election. The lack of a credible commitment to a choice of $r$ implies that pre-election promises carry no weight with single-issue voters, who recognise that politicians can deviate ex post. The only opportunity for candidates to convey information to voters regarding their preferences over trade policy, is through policy decisions made when in power. Voters can update their beliefs on the basis of the incumbent's historical trade policy decisions and thus condition their vote on the history of the elections game. It is this feature of the political agency model that can give rise to strategic behaviour by political incumbents.

Consider the incentives of swing voters in the election for the period two presidency, given the policy change strategy of free-trader incumbents described above. Protectionist and free trade voters maximise their expected payoff by supporting the candidate with the highest probability of implementing $r=1$ and $r=0$, respectively, in their second term. Consider a free-trader incumbent who can improve the probability of winning a majority of electoral college votes if protectionists support his platform (and free traders support the challenger). If nature draws $c_{H}$, the incumbent sets $r=0$, thus revealing himself as a free trader and gaining the support of $\gamma_{F}^{s}$ voters in all states over the continuum. Protectionists support the challenger who is a free-trader with probability $1-\pi$. If $c_{L}$ is drawn, the $D$ free-trader incumbent strategically sets $r=1$ to build a reputation as a protectionist.

The observed first-term trade policy choice provides voters with information with which they update their beliefs about the preferences of the incumbent. Let $\widetilde{\pi}$ denote the updated probability, derived from Bayes' rule, where:

$$
\begin{aligned}
\tilde{\pi} & =\operatorname{Pr}\left(r=1 \text { in } 2^{\text {nd }} \text { term } \mid r=1 \text { in } 1^{\text {st }} \text { term }\right) \\
& =\frac{\operatorname{Pr}\left(r=1 \text { in } 2^{\text {nd }} \text { term }\right) \operatorname{Pr}\left(r=1 \text { in } 1^{\text {st }} \text { term } \mid r=1 \text { in } 2^{\text {nd }} \text { term }\right)}{\operatorname{Pr}\left(r=1 \text { in } 1^{\text {st }} \text { term }\right)} \\
& =\frac{\pi}{\pi+(1-\pi) p}
\end{aligned}
$$

Since politicians set their preferred trade policy when the term limit is binding, the probability that trade protection is set in the second term is the probability that any randomly selected politician is a protectionist, i.e. $\pi$. Moreover, if the incumbent protects in his second term, he is revealed to be a protectionist

\footnotetext{
${ }^{7}$ Besley and Case (1995) as well as List and Sturm (2006) examine how term limits change the incentives of politicians to build a reputation, with significant effects on policy choice. In this chapter, the optimality of a reputation building strategy depends on both the measure and distribution of $P$ voters relative to $F$ voters across states in the electoral college.
} 
and thus protects in the first term with probability 1 . The probability that the industry in question is protected in the incumbent's first term in office is the composite probability of being a protectionist, $\pi$, or being a free trader who had low cost draw, $(1-\pi) p$.

Swing voters contrast $\tilde{\pi}$, the updated probability of the incumbent being a protectionist, with the probability that a randomly selected challenger sets $r=1$ in his first term of office. For a sufficiently small value ${ }^{8}$ for $p$, first term protectionism is a sufficiently strong signal of protectionist preferences, so that:

$$
\widetilde{\pi}>\pi+(1-\pi) p
$$

For the rest of the paper we assume $p$ is sufficiently small to satisfy condition (4) so as to ensure that $\gamma_{P}^{s}$ support the incumbent government if trade protection is implemented in the first term, while $\gamma_{F}^{s}$ voters support the challenger, given politicians' strategies in equilibrium. The optimality of swing voters' re-election strategies is confirmed in Appendix A, where these are shown to maximise voters' value functions, given politicians' strategies.

The next section examines how a shift from free trade in the first term of office affects the incumbent's probability of winning a majority in any state $s$, given its characteristics. State level probability changes are translated into electoral college votes that in turn allow the change in probability of re-election to be derived. We examine incentives for trade protection and confirm that politicians' and voters' strategies constitute a Markov Perfect equilibrium of the game.

\subsection{Trade Policy and State-Level Majority}

Recall that in each state $s, \sum_{k} \gamma_{k}^{s}=1$. Let $\omega_{p}^{s}=\left(\gamma_{D}^{s}-\gamma_{R}^{s}\right)$ represent the lead of the $D$ candidate in state $s$, referred to as the 'political lead', and $\omega_{t}^{s}=$ $\left(\gamma_{P}^{s}-\gamma_{F}^{s}\right)$ represent the excess of $P$ voters relative to $F$ voters, referred to as the 'trade policy lead'. A state with a larger proportion of Republican voters than Democrat voters has a negative political lead, while a state with a larger proportion of free trade supporters relative to protectionists has a negative trade policy lead.

Let $\rho_{\mid r=0}^{s}$ denote the probability that the incumbent wins a majority in state $s$ given free trade in the first term, and $\rho_{\mid r=1}^{s}$ if trade protection is implemented. Given voters' strategies, protectionists vote for the incumbent if trade protection is implemented in the first term of office and for the challenger otherwise, and vice versa for free-trader voters.

Consider a Democrat incumbent in his first term of office. Consider the implications of switching from free-trade to trade protection in his first term

\footnotetext{
${ }^{8}$ List and Sturm (2006) identify two conflicting effects. Applied to our trade policy game, these are: first, an incentive effect that follows from the term limit assumption that lowers the probability of $r=1$ in the second term, since a free-trader will set $r=0$ with certainty; and second, a selection effect that raises the likelihood of $r=1$, since re-elected politicians in their second term of office are more likely to be protectionist. The size of $p$ determines which of the two effects dominates.
} 
of office on the probability of winning a majority in state $s$. The $D$ incumbent gains $\gamma_{D}^{s}+\gamma_{F}^{s}+\nu^{s}$ by setting $r=0$ in his first term, while the $R$ challenger gains the remaining votes. The incumbent wins a majority of votes in state $s$, given $r=0$, if $\gamma_{D}^{s}+\gamma_{F}^{s}+\nu^{s}>\gamma_{R}^{s}+\gamma_{P}^{s}-\nu^{s}$, that implies $\varepsilon^{s}$ must exceed $\omega_{t}^{s}-\omega_{p}^{s}$. If the $D$ incumbent sets $r=1$, he gains $\gamma_{D}^{s}+\gamma_{P}^{s}+\nu^{s}$ and the remaining $\gamma_{R}^{s}+\gamma_{F}^{s}$ $-\nu^{s}$ are gained by the $R$ challenger. Hence, a majority in state $s$ is won if $\varepsilon^{s}$ exceeds $-\omega_{t}^{s}-\omega_{p}^{s}$. It follows from the distribution ${ }^{9}$ of $\varepsilon^{s}$ that:

$$
\begin{aligned}
& \rho_{\mid r=0}^{s}=\operatorname{Pr}\left(\varepsilon^{s}>\omega_{t}^{s}-\omega_{p}^{s}\right)=H\left(\omega_{p}^{s}-\omega_{t}^{s}\right) \\
& \rho_{\mid r=1}^{s}=\operatorname{Pr}\left(\varepsilon^{s}>-\omega_{t}^{s}-\omega_{p}^{s}\right)=H\left(\omega_{p}^{s}+\omega_{t}^{s}\right)
\end{aligned}
$$

Now consider the probabilities $\rho_{\mid r=0}^{s}$ and $\rho_{\mid r=1}^{s}$ for a Republican incumbent. The $R$ incumbent gains $\gamma_{R}^{s}+\gamma_{F}^{s}-\nu^{s}$ by setting $r=0$ in his first term, while the $D$ challenger gains the remaining votes. A majority is won by $R$ in state $s$ if $\gamma_{R}^{s}+\gamma_{F}^{s}-\nu^{s}>\gamma_{D}^{s}+\gamma_{P}^{s}+\nu^{s}$, that is, if $\varepsilon^{s}<-\left(\omega_{t}^{s}+\omega_{p}^{s}\right)$. If the Republican sets $r=1$ in his first term, he gains $\gamma_{R}^{s}+\gamma_{P}^{s}-\nu^{s}$ and the remaining $\gamma_{D}^{s}+\gamma_{F}^{s}$ $+\nu^{s}$ are gained by the $D$ challenger. A majority in state $s$ is won if $\varepsilon^{s}<\omega_{t}^{s}-\omega_{p}^{s}$. An $R$ incumbent's probability of majority can thus be expressed by as:

$$
\begin{aligned}
& \rho_{\mid r=0}^{s}=\operatorname{Pr}\left(\varepsilon^{s}<-\omega_{t}^{s}-\omega_{p}^{s}\right)=1-H\left(\omega_{p}^{s}+\omega_{t}^{s}\right) \\
& \rho_{\mid r=1}^{s}=\operatorname{Pr}\left(\varepsilon^{s}<\omega_{t}^{s}-\omega_{p}^{s}\right)=1-H\left(\omega_{p}^{s}-\omega_{t}^{s}\right)
\end{aligned}
$$

Let $\Delta \rho^{s}=\rho_{\mid r=1}^{s}-\rho_{\mid r=0}^{s}$ denote the change in the probability of winning a majority in $s$ through trade protection. Combining (5) and (6), as well as (7) and (8), yields that $\Delta \rho^{s}=H\left(\omega_{p}^{s}+\omega_{t}^{s}\right)-H\left(\omega_{p}^{s}-\omega_{t}^{s}\right)$ for both a Democrat incumbent and a Republican incumbent. The incentives for trade policy implementation are thus symmetric for incumbents of either party. Furthermore, symmetry of $h\left(\varepsilon^{s}\right)$ allows $\Delta \rho^{s}$ to be summarised by:

$$
\Delta \rho^{s}=H\left(\left|\omega_{p}^{s}\right|+\omega_{t}^{s}\right)-H\left(\left|\omega_{p}^{s}\right|-\omega_{t}^{s}\right)
$$

Equation (9) shows that the impact of the implementation of first term trade protection by an incumbent, of either party, on the probability of that incumbent winning a majority in state $s$ depends on two factors. First, the absolute value of the political lead, $\left|\omega_{p}^{s}\right|$, that reflects the degree of electoral competition in state $s$, and second, the trade policy lead, $\omega_{t}^{s}$, the reflects the 'swingness' of state $s$, as measured by the difference between protectionist voters and free-trader voters.

\footnotetext{
${ }^{9}$ Voter turnout across US states has been repeatedly found to be positively correlated with the closeness of electoral competition (Geys, 2006, Matsusaka, 1993, Cox and Munger, 1989). This suggests that the state-specific turnout shock may plausibly depend on $\omega^{s}$. For simplicity and so as to be able to characterise the political equilibrium, we abstract from this and maintain the assumption of independently and identically distributed state-specific shocks.
} 
For any given level of electoral competition, the magnitude and sign of $\omega_{t}^{s}$ determine the extent to which trade policy can 'swing' the state in the incumbent's favour. If $\gamma_{P}^{s}>\gamma_{F}^{s}$, then deviating from free-trade to trade protection improves the incumbent's probability of a majority, so $\Delta \rho^{s}>0$. Conversely, if $\gamma_{P}^{s}<\gamma_{F}^{s}$ then an incumbent of either party worsens the probability of winning a majority of votes in $s$, so $\Delta \rho^{s}<0$. Finally, if $P$ and $F$ voters have equal measure in state $s$, then $\omega_{t}^{s}=0$ and trade policy has no power in altering electoral outcomes for state $s$. Moreover, the greater the trade policy lead (lag), the greater the impact on the probability of a majority in $s$.

For a given trade policy lead, $\omega_{t}^{s}$, the closer is electoral competition between the candidates, the larger the impact of the existing swing voters on $\Delta \rho^{s}$. To see why this is the case, consider that distribution $h\left(\varepsilon^{s}\right)$ is symmetric around 0 and single-peaked. For a given $\omega_{t}^{s}$, as $\left|\omega_{p}^{s}\right| \rightarrow 0$, the probability gain is from the centre of the distribution, implying a larger $\Delta \rho^{s}$.

The pair of leads, $\left(\omega_{p}^{s}, \omega_{t}^{s}\right)$, therefore provides a complete description of state $s$, in terms of assessing the probability of it being won by either candidate. The discussion has shown that in states where $\gamma_{P}^{s}>\gamma_{F}^{s}$ the incumbent stands to improve the probability of winning a majority, while chances are worsened in states where $\gamma_{P}^{s}<\gamma_{F}^{s}$. States where $\gamma_{P}^{s}=\gamma_{F}^{s}$ are neutral to the trade policy decision. In a multi-jurisdictional setting, the implications of the trade policy decision for incumbents' overall re-election probability depends crucially on the distribution of trade policy and political leads across states in the electoral college. If some states have more $P$ than $F$ voters, and others the converse, the incumbent stands to worsen his chances of winning certain electoral college votes and improve the probability of winning others. The next section turns to the question of aggregation of these effects and characterises the probability of the incumbent winning the election overall.

\subsection{Trade Policy in the Electoral College}

Section 2.3 establishes how the trade policy lead and degree of electoral competition in a state determine how the incumbent's first term policy decision alters his subsequent probability of winning the electoral college vote of that state. This section examines how the distribution of state probability changes, $\Delta \rho^{s}$, arising from pairs of leads $\left(\omega_{p}^{s}, \omega_{t}^{s}\right)$, can be translated into a measure of electoral college votes. The conditions under which reputation-building occurs in the political equilibrium are then characterised.

The law of large numbers implies that if each state along a continuum is subject to an identically distributed and independent shock $\varepsilon^{s}$ described by a particular distribution, $h\left(\varepsilon^{s}\right)$, then the distribution of realised shocks over the infinite number of states along the continuum is exactly described by $h\left(\varepsilon^{s}\right)$. This implies that if all states over a continuum have identical $\left|\omega_{p}^{s}\right|$ and $\omega_{t}^{s}$, then $\Delta \rho^{s}=H\left(\left|\omega_{p}^{s}\right|+\omega_{t}^{s}\right)-H\left(\left|\omega_{p}^{s}\right|-\omega_{t}^{s}\right)$ not only describes the change in the incumbent's probability of winning the electoral college vote of each state $s$, but also describes the change in electoral college votes actually won over the continuum of unit length. 
There is no aggregate uncertainty, despite the individual uncertainty reflected in the state-specific shocks, as a result of the infinite nature of states along the continuum. It follows that in the absence of an additional national shock, there is no aggregate uncertainty over the continuum and election outcomes can be predicted deterministically for different policy choices. To add smoothness to our results, and capture the uncertainty of election outcomes, we introduce aggregate uncertainty in the model through the national pro-incumbent shock $\eta$, distributed by $f(\eta)$. The distribution of shock $\eta$ is assumed to be symmetric around 0 and single-peaked, and distributed over a sufficiently wide support so that no candidate can be certain of a majority of electoral college votes.

To apply the law of large numbers and be able to convert changes in probability into changes in electoral college votes won, it must be the case that $\left|\omega_{p}^{s}\right|$ and $\omega_{t}^{s}$ are identical for all states over the continuum. Assuming all states are identical, however, removes all interesting effects that can arise from having a non-uniform distribution of $\left|\omega_{p}^{s}\right|$ and $\omega_{t}^{s}$. We thus choose to 'discretise' the continuum into $N$ state 'types', each forming a sub-continuum of the overall continuum of states. States of a given type have identical $\left|\omega_{p}^{s}\right|$ and $\omega_{t}^{s}$, but states from different types may differ in their characteristics. Since there are infinitely many states in a continuum of small measure and a continuum of large measure, it follows that we can apply the law of large numbers on a type-bytype basis. Hence the analysis is facilitated greatly through the assumption of a continuum of states, while the discretization of the continuum into types allows us to investigate the role of voter distribution in a tractable way.

Let there be $N$ state types, denoted by $n$, where $n=\{1,2, \ldots, N\}$. All states of a given type are assumed to be identical in terms of their degree of electoral competition $\left|\omega_{p}^{n}\right|$ and the trade policy lead $\omega_{t}^{n}$. Let $\phi_{n} \geq 0$ denote the proportion of states $s$ that are of type $n$, such that $\sum_{n=1}^{N} \phi_{n}=1$. Moreover, suppose state types are ranked in declining $\left|\omega_{p}^{n}\right|$ such that $\left|\omega_{p}^{j}\right| \geq\left|\omega_{p}^{k}\right|$, where $k>j$ and $k, j \in\{1,2, \ldots, N\}$. Further assume $\left|\omega_{p}^{1}\right| \leq 1$ and $\left|\omega_{p}^{N}\right| \geq 0$.

The ranking of discrete state types over the continuum implies that the distribution of $\left|\omega_{p}\right|$ across the electoral college is a step function, as illustrated in figure (1). The distribution of states across the electoral college can be changed through (i) the relative weight of state types in the electoral college through $\phi_{n}$, (ii) the finite number of types $N$, and (iii) the distribution of $\left|\omega_{p}^{n}\right|$.

Let $\Delta v^{n}$ denote the change in electoral college votes of type $n$ won by the incumbent as a result of implementing trade protection in his first term. Moreover, let $\Delta v=\sum_{n=1}^{N} \Delta v^{n}$ denote the total change in electoral college votes over the whole continuum of states from a deviation from preferred trade policy in the first term. For any state of type $n$, the change in the incumbent's probability of winning a majority by deviating from free trade is $\Delta \rho^{n}$, where $\Delta \rho^{n}=H\left(\left|\omega_{p}^{n}\right|+\omega_{t}^{n}\right)-H\left(\left|\omega_{p}^{n}\right|-\omega_{t}^{n}\right)$. It follows from the law of large numbers that $\phi_{n} \Delta \rho^{n}$ gives the change in electoral college votes of type $n$ won by the incumbent. Aggregating over all state types yields: 


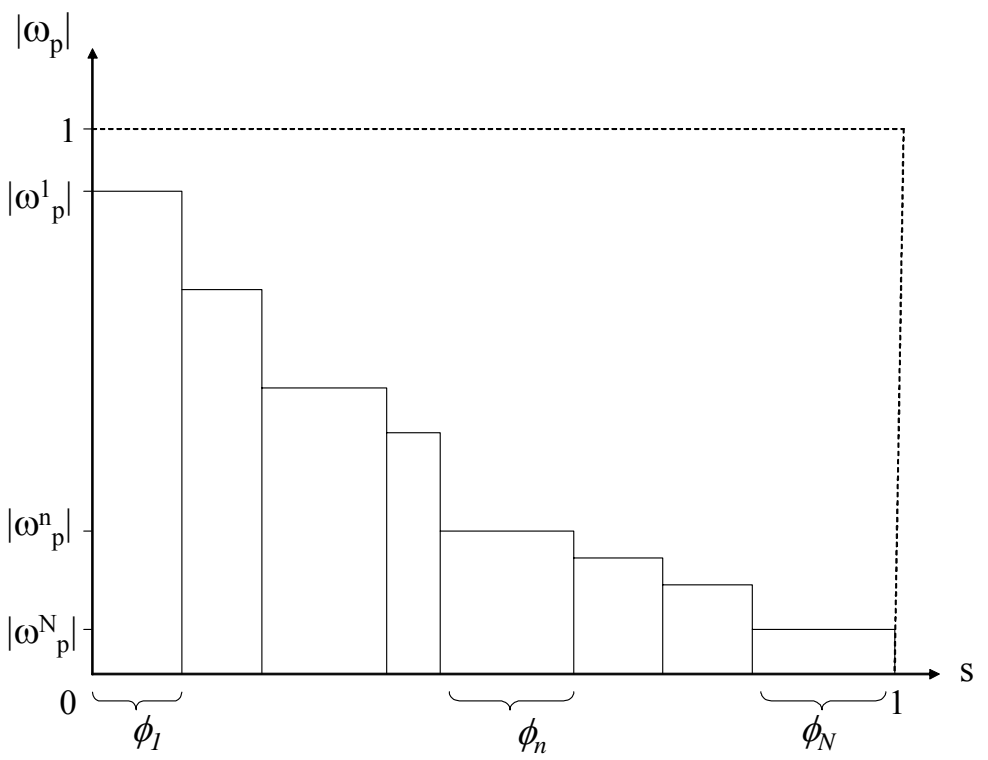

Figure 1: Representation of $\mathrm{N}$ state types in the continuum.

$$
\Delta v=\sum_{n=1}^{N} \Delta v^{n}=\sum_{n=1}^{N} \phi_{n} \Delta \rho^{n}
$$

It follows from (10) that $\Delta v$ is a weighted sum of the state type probability changes. The incumbent may gain or lose electoral college votes from setting $r=$ 1 depending on sign and magnitude of $\Delta \rho^{n}$ for each state type, and the weight of that state type in the electoral college, given by $\phi_{n}$. If the characteristics and distribution of state types are such that $\Delta v<0$ overall, then the free-trader incumbent cannot improve his chances of re-election through the implementation of trade policy and always selects $r=0$ in his first term. The reputation building equilibrium described in section 2.2 requires that $\Delta v>0$, so that free-trader incumbents gain from the shift from free trade. As discussed, there are two symmetric reputation-building equilibria, where $\Delta v>0$ and where $\Delta v<0$, respectively. We focus on the former, where free-trader incumbents may have an incentive to implement trade protection. In the latter, a protectionist incumbent may choose to build a reputation as a free-trader by abstaining from trade protection in his first term. We return to this issue in the next section where we examine how a redistribution of swing voters gives results in a shift from one equilibrium to another.

It is appealing to interpret $\Delta v$ in (10) as the change in electoral college votes when there are $N$ states (rather than $N$ measures of states), each with $\phi_{n}$ 
electoral college votes, where $\Delta \rho^{n}$ represents the change in the probability of winning the electoral college votes of state $n$. This interpretation is intuitive but important conceptual differences exist between the discrete state interpretation and the continuous measures of states assumed in the model. Under a discrete state interpretation, the electoral votes of a state $n$, are won or lost as a block $\phi_{n}$, while in the continuous measures of state types imply that proportions of votes $\phi_{n}$ are won or lost. Hence, with a continuum of states, $\Delta v$ reflects the actual change in electoral college votes won by the incumbent, not the expected change in electoral college votes.

Recall that $u$ is the pro-incumbent shock in electoral college votes won. Moreover, let $v_{I}^{r}$ denote the electoral college votes won by the incumbent when he sets trade policy $r$ in his first term of office. Similarly, $v_{C}^{r}$ denote those won by the challenger, given $r$. Let $\omega_{v}^{r}=\left(v_{I}^{r}-v_{C}^{r}\right)$ denote the incumbent's lead over the challenger in the electoral college, given $r$, where $\omega_{v}^{r}$ can take values between -1 and 1 and reflects the degree of electoral competition at the national level.

For the incumbent to be re-elected, given $r$, it must be the case that $v_{I}^{r}+$ $u>v_{C}^{r}-u$. Hence, $2 u=\eta$ must exceed $v_{C}^{r}-v_{I}^{r}$. Finally, let $\theta^{r}$ denote the incumbent's probability of re-election, given trade policy selection $r$ in the first term of office. Given distribution $F(\eta)$ probabilities $\theta^{0}$ and $\theta^{1}$ can be expressed as:

$$
\begin{aligned}
& \theta^{0}=\operatorname{Pr}\left(\eta>v_{C}^{0}-v_{I}^{0}\right)=1-F\left(v_{C}^{0}-v_{I}^{0}\right)=F\left(\omega_{v}^{0}\right) \\
& \theta^{1}=\operatorname{Pr}\left(\eta>v_{C}^{1}-v_{I}^{1}\right)=1-F\left(v_{C}^{1}-v_{I}^{1}\right)=F\left(\omega_{v}^{1}\right)
\end{aligned}
$$

Since $\Delta v$ reflects the change in electoral college votes won by the incumbent from a policy shift, it follows that $v_{I}^{1}=v_{I}^{0}+\Delta v$ and $v_{C}^{1}=v_{C}^{0}-\Delta v$. Hence, $\omega_{v}^{1}=v_{I}^{1}-v_{C}^{1}=v_{I}^{0}-v_{C}^{0}+2 \Delta v=\omega_{v}^{0}+2 \Delta v$. The re-election probabilities can thus be re-written as:

$$
\begin{aligned}
& \theta^{0}=F\left(\omega_{v}^{0}\right) \\
& \theta^{1}=F\left(\omega_{v}^{0}+2 \Delta v\right)
\end{aligned}
$$

Defining $\Delta \theta$ as the change in re-election probability from a policy shift, it follows directly from (13) and (14) that $\Delta \theta=\theta^{1}-\theta^{0}=F\left(\omega_{v}^{0}+2 \Delta v\right)-F\left(\omega_{v}^{0}\right)$. Furthermore, symmetry of $f(\eta)$ allows $\Delta \theta$ to be summarised by:

$$
\Delta \theta=F\left(\left|\omega_{v}^{0}\right|+2 \Delta v\right)-F\left(\left|\omega_{v}^{0}\right|\right)
$$

It follows from (15) that the incumbent enjoys an improvement in reelection probability $(\Delta \theta>0)$ from the implementation of trade protection provided there is an overall gain in electoral college votes from the policy $(\Delta v>0)$. If $\Delta v>0$, then the expected payoff from implementing trade protection in the first term is $(\Delta \theta) \beta \zeta$ for a free-trader incumbent of either party. For $r=1$ to be an optimal strategy, the expected payoff must exceed the incumbent's utility cost draw. Since $(\Delta \theta) \beta \zeta<\beta \zeta$ and $c_{H}>\beta \zeta$, the analysis confirms that a freetrader incumbent with a high utility cost draw never finds it optimal to deviate 
from free trade. If a low utility cost $c_{L}$ is drawn, then $(\Delta \theta) \beta \zeta$ must be larger than $c_{L}$ for the reputation-building strategy to be optimal.

In the symmetric equilibrium where $\Delta v<0$, a protectionist incumbent improves his re-election probability by setting $r=0$ in his first term. Since $\Delta \theta$ is defined as the change in re-election probability from a policy shift, then $\Delta \theta=\theta^{0}-\theta^{1}>0$. If the expected payoff exceeds $c_{L}$ then his reputation-building strategy is optimal.

Proposition 1 If $(\Delta \theta) \beta \zeta>c_{L}$, then there is a unique equilibrium in which incumbent politicians with a low utility cost draw $\left(c_{L}\right)$ deviate from their preferred trade policy in their first term of office if this increases their re-election probability and follow their private preferences otherwise.

Proof. It follows from (9) that $\Delta \rho^{n}=H\left(\left|\omega_{p}^{n}\right|+\omega_{t}^{n}\right)-H\left(\left|\omega_{p}^{n}\right|-\omega_{t}^{n}\right)$ is the change in the probability of winning the electoral college vote of a state of type $n$. The resulting change in type $n$ electoral college votes won is $\phi_{n} \Delta \rho^{n}$. Aggregating over state types gives the total change in electoral college votes from a policy shift, $\Delta v=\sum_{n=1}^{N} \phi_{n} \Delta \rho^{n}$. If $\Delta v>0$, then a free-trader incumbent of either party enjoys a gain in re-election probability $\Delta \theta$ from setting $r=1$ in his first term of office. Provided a low cost is drawn and $(\Delta \theta) \beta \zeta>c_{L}$, the $F$ incumbent enjoys a positive net expected payoff from setting $r=1$, so finds it optimal to deviate from his preferred private policy. If a high utility cost $c_{H}$ is drawn by an $F$ incumbent or the gain in re-election probability $\Delta \theta$ is not sufficiently large for $(\Delta \theta) \beta \zeta>c_{L}$ to be satisfied, then the incumbent sets his preferred policy, free trade. In this equilibrium, a protectionist incumbent cannot increase his re-election probability through a policy shift, so always finds it optimal to follow his private preferences and set $r=1$.

Conversely, if $\Delta v<0$, then a protectionist incumbent of either party enjoys a gain in re-election probability $\Delta \theta$ from setting $r=0$ in his first term of office. Provided a low cost is drawn and $(\Delta \theta) \beta \zeta>c_{L}$, the $P$ incumbent enjoys a positive net expected payoff from setting $r=0$, so finds it optimal to deviate from his preferred private policy. If a high utility cost $c_{H}$ is drawn by a $P$ incumbent or the gain in re-election probability $\Delta \theta$ is not sufficiently large for $(\Delta \theta) \beta \zeta>c_{L}$ to be satisfied, then the incumbent sets his preferred policy, trade protection. In this equilibrium, a free-trader incumbent cannot increase his reelection probability through a policy shift, so always finds it optimal to follow his private preferences and set $r=1$.

For a given distribution of voters in the electoral college, and thus given $\Delta v$, the equilibrium in which reputation-building forms part of incumbent's optimal strategies is the unique equilibrium. A proof of uniqueness can be found in Appendix B.

Inspection of (15) reveals that the reputation-building equilibrium depends on two key national-level parameters of the model. First, the closeness of electoral competition at the national level, as measured by $\left|\omega_{v}^{0}\right|$ and second, the gain in electoral college votes $\Delta v$ from a policy shift. The characteristics of $f(\eta)$ imply that a closer degree of electoral competition between candidates at 
the national level, the greater the probability gain from an increase in electoral college votes from a policy shift.

Intuitively, the closer the competition between the two candidates, that is the smaller is $\left|\omega_{v}^{0}\right|$, then the more likely it is that the pro-incumbent shock perturbs the election outcome. Since the pro-incumbent shock is more likely to be near 0 , a given gain in electoral college votes through a strategic trade policy decision is more beneficial the closer $\left|\omega_{v}^{0}\right|$ is to 0 .

Conversely, relatively weak electoral competition, reflected by high $\left|\omega_{v}^{0}\right|$, implies that one of the candidates has a large lead in electoral college votes over the other. The probability that a sufficiently large shock is realised to change the election outcome is relatively low. A gain $\Delta v$ implies a smaller shock is sufficient to change the election result, but the further from 0 is the initial difference in electoral college votes, the smaller the associated gain in probability.

Furthermore, for any given degree of national electoral competition, the greater the increase in electoral college votes $\Delta v$ that can be won through a policy shift, the greater is the incumbent's gain in re-election probability. Intuitively, the more votes that can be 'swung' at the national level from trade policy, the larger the impact of the trade policy decision on re-election probability.

A change in either $\left|\omega_{v}^{0}\right|$ or $\Delta v$ has an impact on re-election probability $\Delta \theta$ and thus on the likelihood that condition ${ }^{10}(\Delta \theta) \beta \zeta>c_{L}$ is satisfied. These results are summarised in proposition (2).

Proposition 2 An increase in the number of electoral college votes that can be won by deviating from preferred trade policy $(\Delta v)$ or an increase in electoral competition at the national level (lower $\left|\omega_{v}^{0}\right|$ ) make reputation-building through the strategic selection of trade policy more likely.

Proof. Consider a distribution of voters such that $\Delta v>0$. It follows directly from $\Delta \theta=F\left(\left|\omega_{v}^{0}\right|+2 \Delta v\right)-F\left(\left|\omega_{v}^{0}\right|\right)$ that an increase in $\Delta v$, ceteris paribus, increases the change in the incumbent's re-election probability from the implementation of trade protection. Moreover, since $f(\eta)$ is symmetric around 0 and single-peaked, $\Delta \theta$ increases as $\left|\omega_{v}^{0}\right| \rightarrow 0$. A higher $\Delta \theta$ from either increase makes it more likely that condition $(\Delta \theta) \beta \zeta>c_{L}$ is satisfied, and thus that reputation building takes place.

Propositions (1) and (2) confirm the same properties apply in the multijurisdictional framework as in the related literature with one jurisdiction. Namely, that there exists a unique reputation-building equilibrium that is more likely the larger the number of votes that can be swung through a policy decision, and the closer is electoral competition between candidates.

The multi-jurisdictional framework extends the literature in two ways. First, the electoral college structure provides new insights into how state-level characteristics in the electoral college combine to influence the incentives for strategic trade protection at the national level. This provides for a more nuanced analysis of how swing-voters affect policy decisions. Second, the framework adds a

\footnotetext{
${ }^{10} \mathrm{An}$ increase in the discounted ego-rent, $\beta \zeta$, or decrease in $c_{L}$ also increase the likelihood of there being a reputation-building equilibrium.
} 
spatial dimension that allows distributional effects to be examined in a highly tractable way. The analysis delivers three new propositions that describe how the distribution of voters in the electoral college influence trade policy decisions. These effects are analysed in the next section.

\subsection{Distribution of Voters and Electoral Incentives}

Section 2.4 establishes that the reputation building equilibrium depends on parameters, $\left|\omega_{v}^{0}\right|$ and $\Delta v$, that contribute to the change in the incumbent's reelection probability arising from a first term policy shift. While these nationallevel parameters confirm the importance of electoral competition and the change in electoral college votes won as key determinants, they represent summary statistics of the underlying state-level characteristics in the electoral college. Expressing $\Delta \theta$ in terms of state-level parameters gives rise to proposition (3).

Proposition 3 The likelihood of strategic trade policy implementation depends on the distribution of swing voters and ideologists within states of a given type $\left(\left|\omega_{p}^{n}\right|, \omega_{t}^{n}\right)$, the distribution of state types in the electoral college $\left(\phi_{n}\right)$ and the probability distributions of state-level $\left(H\left(\varepsilon^{s}\right)\right)$ and national shocks $(F(\eta))$.

Proof. Consider the change in re-election probability summarised by (15). Recall that $\Delta v=\sum_{n=1}^{N} \phi_{n} \Delta \rho^{n}$. This can be expressed in terms of state-level characteristics by substituting for $\Delta \rho^{n}$. This yields:

$$
\Delta v=\sum_{n=1}^{N} \phi_{n} \Delta \rho^{n}=\sum_{n=1}^{N} \phi_{n}\left(H\left(\left|\omega_{p}^{n}\right|+\omega_{t}^{n}\right)-H\left(\left|\omega_{p}^{n}\right|-\omega_{t}^{n}\right)\right)
$$

Moreover, electoral competition at the national level $\left|\omega_{v}^{0}\right|=\left|v_{I}^{0}-v_{C}^{0}\right|$, where $v_{I}^{0}$ and $v_{C}^{0}$ are the electoral college votes won by the incumbent and challenger, respectively, under free trade in the first term. $v_{I}^{0}$ is the weighted sum of electoral college votes won by state type, when $r=0$. Thus $v_{I}^{0}=\sum_{n=1}^{N} \phi_{n} \rho_{\mid r=0}^{n}$. Moreover, since $v_{I}^{0}+v_{C}^{0}=1$, it is straightforward to express the challenger's electoral college votes as $v_{C}^{0}=1-\sum_{n=1}^{N} \phi_{n} \rho_{\mid r=0}^{n}$. Combining these allows national-level electoral competition to be expressed in terms of state-level characteristics:

$$
\omega_{v}^{0}=2 \sum_{n=1}^{N} \phi_{n} \rho_{\mid r=0}^{n}-1=2 \sum_{n=1}^{N} \phi_{n} H\left(\left|\omega_{p}^{n}\right|-\omega_{t}^{n}\right)-1
$$

Substituting (16) and (17) into (15) allows the incumbents re-election probability to be expressed in terms of state-level variables and distributional parameters:

$$
\begin{aligned}
\Delta \theta & =F\left(\left|\omega_{v}^{1}\right|\right)-F\left(\left|\omega_{v}^{0}\right|\right) \\
& =F\left(2 \sum_{n=1}^{N} \phi_{n} H\left(\left|\omega_{p}^{n}\right|+\omega_{t}^{n}\right)-1\right)-F\left(2 \sum_{n=1}^{N} \phi_{n} H\left(\left|\omega_{p}^{n}\right|-\omega_{t}^{n}\right)-1\right)
\end{aligned}
$$


Inspection of (18) shows that the change in re-election probability, and thus the likelihood of strategic trade policy implementation, hinges on (i) the distribution of swing voters and ideologists within states of a given type, summarised by $\left(\left|\omega_{p}^{n}\right|, \omega_{t}^{n}\right)$, (ii) the distribution of state types in the electoral college, reflected by proportions $\phi_{n}$ and (iii) the distributions of state-level and national-level shocks, $H\left(\varepsilon^{s}\right)$ and $F(\eta)$.

To show how the spatial position of swing voters can influence policy decisions, we consider two redistribution experiments that satisfy the following conditions:

1. The aggregate population of each voter type in the electoral college is kept constant. In particular, if we let $\Gamma_{k}$ denote the total measure of $k$ voters in the electoral college, then the distribution of $k$ voters across $n$ state types, as reflected by $\gamma_{k}^{n}$, must satisfy the following condition:

$$
\Gamma_{k}=\sum_{n=1}^{N} \phi_{n} \gamma_{k}^{n}, \text { where } k \in\{D, R, F, P\}
$$

2. All states always have a unit measure of voters, so $\sum_{k} \gamma_{k}^{n}=1$. This implies that an increase in the measure of voters of a particular type in a state, must be accompanied by a decrease in voters of some other type. Denoting the total measure of voters by $\Gamma$, conditions 1 and 2 imply that the total measure of voters in the electoral college must be 1:

$$
\Gamma=\sum_{k} \Gamma_{k}=\sum_{k} \sum_{n} \phi_{n} \gamma_{k}^{n}=\sum_{n} \phi_{n} \sum_{k} \gamma_{k}^{n}=1
$$

3. Feasibility constraints regarding pairs of values $\left(\omega_{p}^{n}, \omega_{t}^{n}\right)$ for all state types $n$ are adhered to. To see how these apply, consider pair $\left(\left|\omega_{p}^{n}\right|, \omega_{t}^{n}\right)$ that describes states of type $n$. Since the sum of all voter types is 1 in each state, there is a finite range of values that leads $\omega_{p}^{n}$ and $\omega_{t}^{n}$ may feasibly take. In particular, the larger is the lead in any one dimension, the smaller the scope for variability in the lead in the other dimension. For example, if $\omega_{p}^{n}=1$ (or -1 ), then a state of type $n$ is made up entirely of $D$ voters (or $R$ voters) so $\omega_{t}^{n}=0$. At the other extreme, $\omega_{t}^{n}=1$ (or -1 ) implies $\left|\omega_{p}^{s}\right|=0$. Figure (2) illustrates the set of all feasible combinations of $\left(\omega_{p}^{n}, \omega_{t}^{n}\right)$, given $\sum_{k} \gamma_{k}^{n}=1$. Consider $\left|\omega_{p}^{n}\right|=\alpha$. This implies that $D$ voters exceed $R$ voters by $\alpha$, or vice versa. For example, suppose $\gamma_{D}^{n}=0.4$ and $\gamma_{R}^{n}=0.2$, in states of type $n$, implying a Democratic lead $\omega_{p}^{n}=0.2$. The sum of ideologists is 0.6 , so the swing voters represent 0.4 of each state. If all swing voters are protectionist, then $\omega_{t}^{n}=0.4$, while if all are free-traders, then $\omega_{t}^{n}=-0.4$. Suppose instead that $\omega_{p}^{n}=0.2$ arises from $\gamma_{D}^{n}=0.3$ and $\gamma_{R}^{n}=0.1$. In this case, $\omega_{t}^{n}$ ranges from -0.5 to 0.5 . It is straightforward to see that if there are no $R$ voters at all, then $\omega_{t}^{n}$ ranges from -0.8 to 0.8 . This gives the largest possible range consistent with $\omega_{p}^{n}=\gamma_{D}^{n}=0.2$. Similar reasoning applies for a state where $\omega_{p}^{n}=-0.2$. 
In general, the maximum measure of single-issue voters consistent with $\left|\omega_{p}^{n}\right|=\alpha$ is $1-\alpha$. Hence, the maximum trade policy lead is $\omega_{t}^{n}=1-\alpha$, where all swing voters are protectionists. Conversely, the minimum trade policy lead consistent with $\left|\omega_{p}^{n}\right|=\alpha$ is $\omega_{t}^{s}=\alpha-1$, where all single-issue voters are free-traders. These maximum and minimum leads form the rhombus in figure (2). States with positive measures of all voter types are described by $\left(\omega_{p}^{n}, \omega_{t}^{n}\right)$ that lie inside the rhombus. The discussion can be summarised by the following range for $\omega_{t}^{n}$, given $\left|\omega_{p}^{n}\right|$ :

$$
\omega_{t}^{n} \in[\alpha-1,1-\alpha], \text { if }\left|\omega_{p}^{n}\right|=\alpha, \text { where } \alpha \in[0,1]
$$

Any redistribution of voters across state types must be consistent with (21).

The analysis in the paper up to this point has been concerned with politicians' optimal strategies for a given distribution of voters. The two redistribution experiments in this section address a different set of questions. In particular, how a change in the spatial location of a measure of swing voters can alter the electoral incentives for trade protection of a given industry, whether through variation in the degree of state-level competition across the electoral college, or through institutional parameters, such as variation in the contribution of electoral votes of different state types in the electoral college. While we model the redistribution as a physical migration of voters with fixed preferences, this need not be the case. Preferences of voters may change in a given location, without migration, through changes in the pattern of industrial concentration and employment. The experiments reveal two key distributional determinants of electoral incentives. First, state 'swingness', as measured by the closeness of state-level electoral competition, and second, state 'decisiveness', as measured by the proportion of electoral college votes represented by states of a given type.

Let us define the initial distribution of swing voters prior to any redistribution. This is referred to as the 'benchmark distribution' in the rest of the section. Suppose the $N$ state types are ranked such that $1>\left|\omega_{p}^{1}\right|>. .>\left|\omega_{p}^{n}\right|>$ $. .>\left|\omega_{p}^{N}\right|>0$. Condition (21) implies that the maximum measure of singleissue voters in states of type $n$ consistent with $\left|\omega_{p}^{n}\right|$ is $1-\left|\omega_{p}^{n}\right|$. Assume the maximum feasible measure of single-issue voters is present in all states of types $n$. It follows that the measure of swing voters is increasing with $n$ since $\left|\omega_{p}^{n}\right|$ is decreasing with $n$. Further assume that in the benchmark distribution, the swing voters of each state of type $n$ are split evenly between $P$ and $F$ voters, such that $\gamma_{P}^{n}=\gamma_{F}^{n}=\frac{1}{2}\left[1-\left|\omega_{p}^{n}\right|\right]$. This implies that for each state of type $n, \omega_{t}^{n}=0$, thereby placing the distribution of state types along the $\omega_{p}$ axis in Figure (2). Hence, by construction, the benchmark distribution is characterised by $\Delta \rho^{n}=\Delta v^{n}=0, \forall n$, and thus $\Delta v=\Delta \theta=0$, so trade policy has no impact on re-election probability. The conditions for a reputation-building equilibrium are not satisfied under the benchmark distribution so all incumbents set their preferred trade policy in their first term of office. 


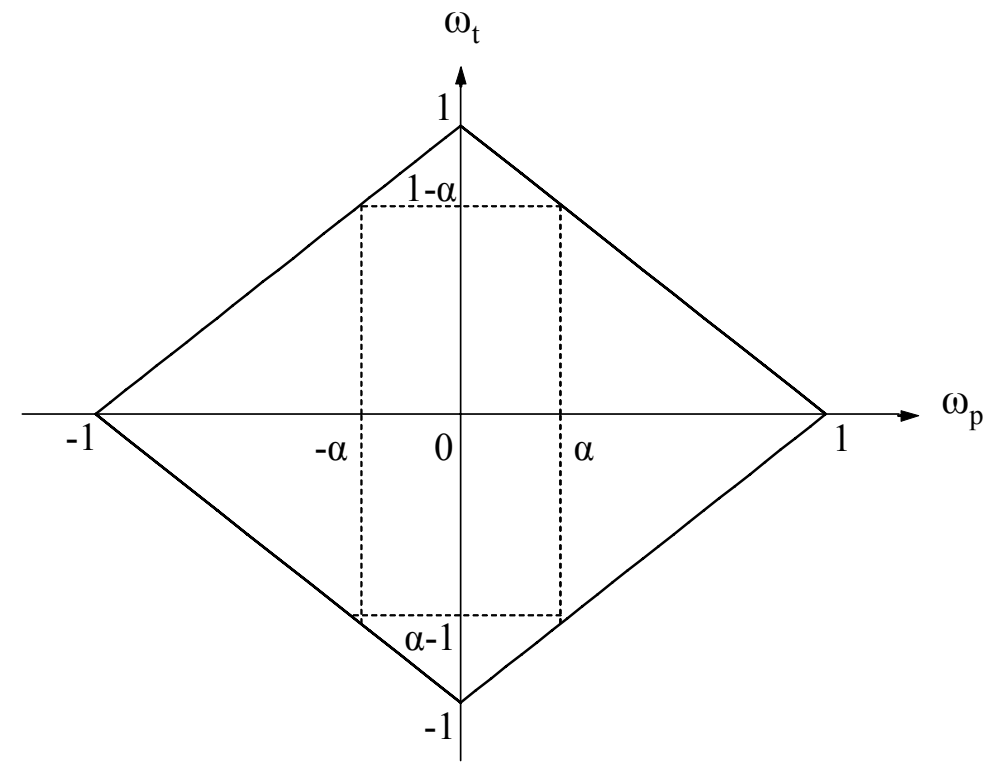

Figure 2: Feasible pairs of political and trade leads.

\subsubsection{Redistribution A - 'Swingness'}

From the benchmark distribution, consider a redistribution of $P$ and $F$ voters that increases the concentration of protectionist voters in states with relatively low $\left|\omega_{p}^{n}\right|$, and vice versa for free-traders. The additional assumption is made that all state types contribute equally to the electoral college ${ }^{11}$, such that $\phi_{n}=\phi, \forall n$. Under these assumptions and provided the redistribution satisfies conditions (1) to $(3)$, the following proposition holds.

Proposition 4 A redistribution of protectionist voters from states with weaker electoral competition (higher $\left|\omega_{p}^{n}\right|$ ) to states with stronger electoral competition (lower $\left|\omega_{p}^{n}\right|$ ) makes it more likely that incumbents engage in strategic trade protection.

Proof. Starting from the initial distribution where there are $\frac{1}{2}\left[1-\left|\omega_{p}^{n}\right|\right]$ protectionists and free traders in each state of type $n$, and state types are ranked in decreasing $\left|\omega_{p}^{n}\right|$, it follows by construction that if a positive measure $k \leq \frac{1}{2}\left[1-\left|\omega_{p}^{i}\right|\right]$ of protectionist voters is redistributed from each state of type $i$ to each state of type $j$, where $i<j$, then:

(i) there are sufficient free-trader voters in each state of type $j$ to replace the $k$ voters redistributed to $j$ from state $i$, since $\frac{1}{2}\left[1-\left|\omega_{p}^{i}\right|\right]<\frac{1}{2}\left[1-\left|\omega_{p}^{j}\right|\right]$.

\footnotetext{
${ }^{11}$ This simplifying assumption controls for the effects on reputation-building incentives arising from different state-type contributions of electoral college votes.
} 
(ii) this exchange of swing voters redistributes $P$ voters towards a measure of states with a closer electoral competition and $F$ voters towards states with weaker electoral competition.

In each $j$ state, the measure of protectionists rises by $k$ and the measure of free traders falls by $k$, hence $\omega_{t}^{j}=\gamma_{P}^{j}-\gamma_{F}^{j}=2 k>0$. Conversely, in each state $i$, $\omega_{t}^{i}=\gamma_{P}^{i}-\gamma_{F}^{i}=-2 k<0$. For all states of type $n$, where $n \neq\{i, j\}, \omega_{t}^{n}=0$. Consider the effects of a deviation from free trade by an incumbent in his first term of office post-redistribution. For states of type $i$ and $j$, the change in a free-trader incumbent's probability of winning a majority from setting $r=1$ in his first term are:

$$
\begin{aligned}
\Delta \rho^{j} & =H\left(\left|\omega_{p}^{j}\right|+2 k\right)-H\left(\left|\omega_{p}^{j}\right|-2 k\right)>0 \\
\Delta \rho^{i} & =H\left(\left|\omega_{p}^{i}\right|-2 k\right)-H\left(\left|\omega_{p}^{i}\right|+2 k\right)<0
\end{aligned}
$$

It follows from (22) and (23) that setting $r=1$ improves the incumbent's probability of winning $j$ state electoral college votes, where $P$ voters exceed $F$, but worsens his chances of winning $i$ state electoral votes where the opposite is the case. The overall change in electoral college votes is given by:

$$
\begin{aligned}
\Delta v & =\phi \Delta \rho^{i}+\phi \Delta \rho^{j}+\phi \sum_{n \neq i, j} \Delta \rho^{n}=\phi\left(\Delta \rho^{i}+\Delta \rho^{j}\right) \\
& =\phi\left[H\left(\left|\omega_{p}^{j}\right|+2 k\right)-H\left(\left|\omega_{p}^{j}\right|-2 k\right)\right]-\phi\left[H\left(\left|\omega_{p}^{i}\right|+2 k\right)-H\left(\left|\omega_{p}^{i}\right|-2 k\right)\right]>0
\end{aligned}
$$

Since $\left|\omega_{p}^{i}\right|>\left|\omega_{p}^{j}\right|$, it follows from the characteristics of $h\left(\varepsilon^{n}\right)$ that the change in electoral college votes won by the incumbent increases, from 0 in the benchmark distribution, to $\Delta v>0$. It follows that from having no effect on re-election probability under the benchmark distribution, the redistribution of protectionists to states with closer electoral competition increases their relative importance in the electoral college, giving rises to an improvement in re-election probability through first term trade protection. Thus an increase in the concentration of protectionists in states with closer electoral competition makes strategic trade protection by incumbents more likely.

The redistribution considered has the dual effect of giving protectionists a lead in one group of states, and free-traders a lead in another group of states, where both groups have equal measure. It is the closeness of electoral competition in the former group of states that gives protectionists a greater weight in the overall assessment of the change in electoral college votes and thus in re-election probability. If the degree of electoral competition were the same in the two state types, then these probability changes would entirely offset each other. It is the difference in the 'swingness' of states across which redistribution takes place that drives the electoral incentives to implement trade protection after the redistribution.

A symmetric redistribution that gives free-traders a lead in groups of states that are more competitive has the opposite effect, such that $\Delta v<0$ holds post-redistribution. This corresponds to the symmetric reputation-building equilibrium where protectionist incumbents override their protectionist views 
and choose free-trade in their first term following a low cost draw. Thus a population-preserving redistribution of swing voters can generate either of the two symmetric reputation-building equilibria.

Intuitively, the preferences of concentrations of swing voters that contribute most in probability terms to election outcomes are given more weight by incumbents when making policy decisions. Moreover, the concentrations that contribute most are those in swing states whose electoral outcome is most uncertain.

\subsubsection{Redistribution B - 'Decisiveness'}

From the benchmark distribution, consider a redistribution of protectionists from states of type $i$ to states of type $j$, where both states types are characterised by the same degree of electoral competition, but where $j$ states represent a larger proportion of electoral college votes than do $i$ states. The assumption that $\left|\omega_{p}^{i}\right|=\left|\omega_{p}^{j}\right|=\left|\omega_{p}\right|$ controls for the 'swingness' effect, while $\phi_{j}>\phi_{i}$ isolates the effect of distributing swing voters across larger or smaller measures of swing states. Suppose that all states of type $n$, where $n \neq\{i, j\}$ remain unchanged.

Starting from $\omega_{t}^{i}=\omega_{t}^{j}=0$, the redistribution described has the effect of concentrating a measure of $F$ voters over a smaller measure of swing states, $i$, while the same volume of $P$ voters is spread evenly over a larger measure of states, $j$, with an identical degree of electoral competitiveness. This gives rise to two conflicting effects on the electoral incentives for trade protection. On the one hand, the relatively large concentration of free-traders in $i$ states implies that a first term protectionist policy reduces the incumbent's probability of winning a majority in each state $i$ by more than the probability gain in winning a majority in each state $j$, where protectionists are less concentrated. On the other hand, $j$ states represent a larger measure of electoral college votes than $i$ states.

Whether the former 'concentration effect' or the latter 'decisiveness effect' dominates determines whether the redistribution increases or decreases the electoral college votes won overall by setting $r=1$ in the first term of office. If $\Delta v>0$ overall, then trade protection is more likely than under the benchmark distribution of swing voters. Otherwise, $\Delta v<0$ and the symmetric reputationbuilding equilibrium is more likely.

The decisiveness effect dominates the concentration effect when the degree of electoral competition is strong in states $i$ and $j$. Intuitively, the greater the swingness of states, the greater the impact in probability terms of even a small lead in protectionist swing voters. Thus the gain in electoral college votes from trade protection is larger, ceteris paribus, when a given measure of protectionist voters is spread over a large measure of highly swing states, than when concentrated over a smaller measure of identical states. Conversely, a small protectionist lead has less potency when electoral competition is weak than when electoral competition is strong, causing the concentration effect to outweigh the decisiveness effect such that the more concentrated $F$ voters in states of type $i$ have a larger impact on electoral college votes won than the 
less concentrated $P$ voters in type $j$ states, under first term strategic trade protection.

Proposition 5 A redistribution of protectionist voters from swing states that constitute a smaller proportion of electoral college votes (lower $\phi$ ) to swing states that constitute a larger proportion of electoral college votes (higher $\phi$ ) makes it more likely that incumbents engage in strategic trade protection.

Proof. Consider state types $i$ and $j$ where $\left|\omega_{p}^{i}\right|=\left|\omega_{p}^{j}\right|=\left|\omega_{p}\right|$ and $\phi_{j}>\phi_{i}$. The total population of swing voters over states of type $i$ is $\phi_{i}\left[1-\left|\omega_{p}\right|\right]$, which is less than the total population of swing voters over $j$ states, given by $\phi_{j}\left[1-\left|\omega_{p}\right|\right]$. Recall that $P$ and $F$ voters are assumed to have equal measure in the benchmark distribution, such that $\Gamma_{P}^{i}=\Gamma_{F}^{i}=\frac{\phi_{i}}{2}\left[1-\left|\omega_{p}\right|\right]$ and $\Gamma_{P}^{j}=\Gamma_{F}^{j}=\frac{\phi_{j}}{2}\left[1-\left|\omega_{p}\right|\right]$. Since, by construction, $\Gamma_{P}^{i}<\Gamma_{F}^{j}$, any redistribution of protectionist voters from $i$ to $j$ states is feasible up to $\Gamma_{P}^{i}$. Suppose $k$ protectionist voters from each state $i$ are redistributed evenly across states $j$. It follows that $\phi_{i} k$ voters are distributed evenly over $\phi_{j}$ states. Let $\lambda$ denote the additional protectionist voters in each state $j$, where $\lambda=\frac{\phi_{i}}{\phi_{j}} k$. Moreover, $\phi_{j} \lambda$ free-traders are redistributed evenly across $i$ states. Thus $\phi_{i} k=\phi_{j} \lambda$. Since $\phi_{j}>\phi_{i}$, it follows that $\lambda<k$.

In each $j$ state, the measure of protectionist rises and free traders falls by $\frac{\phi_{i}}{\phi_{j}} k$. Hence, $\omega_{t}^{j}=\gamma_{P}^{j}-\gamma_{F}^{j}=2 k \frac{\phi_{i}}{\phi_{j}}>0$. Conversely, in each state $i, \omega_{t}^{i}=\gamma_{P}^{i}-\gamma_{F}^{i}=$ $-2 k<0$. For all states of type $n$, where $n \neq\{i, j\}, \omega_{t}^{n}=0$. Consider the effects of a deviation from free trade by an incumbent in his first term of office postredistribution. For states of type $i$ and $j$, the change in a free-trader incumbent's probability of winning a majority from setting $r=1$ in his first term are:

$$
\begin{aligned}
\Delta \rho^{j} & =H\left(\left|\omega_{p}\right|+2 k \frac{\phi_{i}}{\phi_{j}}\right)-H\left(\left|\omega_{p}\right|-2 k \frac{\phi_{i}}{\phi_{j}}\right)>0 \\
\Delta \rho^{i} & =H\left(\left|\omega_{p}\right|-2 k\right)-H\left(\left|\omega_{p}\right|+2 k\right)<0
\end{aligned}
$$

Since $\phi_{j}>\phi_{i}$, it follows that $2 k \frac{\phi_{i}}{\phi_{j}}<2 k$ so the protectionist lead in $j$ states is smaller than the free-trader lead in $i$ states. Inspection of (25) and (26) reveal that setting $r=1$ improves the incumbent's probability of winning each $j$ state electoral college vote but worsens his chances of winning each $i$ state electoral college vote. Moreover, since the degree of electoral competition is the same across the two state types, it follows that $\Delta \rho^{j}<-\Delta \rho^{i}$. This reflects the 'concentration effect' of the redistribution of swing voters across state types of different measure. However, $\phi_{j}>\phi_{i}$, so there is also a 'decisiveness effect' since there are more $j$ state than $i$ state electoral college votes. Using $\lambda=k \frac{\phi_{i}}{\phi_{j}}<k$ and $\phi_{j}=\phi_{i} \frac{k}{\lambda}>\phi_{i}$ for simplification allows the overall change in electoral college votes won by the incumbent as a result of first term protectionist to be 
expressed as:

$$
\begin{aligned}
\Delta v & =\phi_{i} \Delta \rho^{i}+\phi_{j} \Delta \rho^{j}+\sum_{n \neq i, j} \phi_{n} \Delta \rho^{n}=\phi_{i} \Delta \rho^{i}+\phi_{j} \Delta \rho^{j} \\
& =\phi_{i} \frac{k}{\lambda}\left[H\left(\left|\omega_{p}\right|+2 \lambda\right)-H\left(\left|\omega_{p}\right|-2 \lambda\right)\right]-\phi_{i}\left[H\left(\left|\omega_{p}\right|+2 k\right)-H\left(\left|\omega_{p}\right|-2 k\right)\right]
\end{aligned}
$$

Inspection of (27) reveals the trade-off between the two conflicting effects. The first term shows a smaller probability change per $j$ state, with weight $\phi_{i}$ magnified by $\frac{k}{\lambda}$ as a result of the larger scale of electoral college votes. The second term shows the larger probability change for $i$ states weighted only by $\phi_{i}$. The characteristics of $H(\cdot)$ imply that $\Delta v>0$ when electoral competition is sufficiently close. Hence, when states $i$ and $j$ are characterised by low $\left|\omega_{p}\right|$ and thus a high degree of swingness, the redistribution of protectionist voters across a measure of more decisive states makes strategic trade protection more likely.

Propositions (4) and (5) provide new insights concerning how the distribution of voters can influence the decisions of policy makers driven by electoral incentives. The model emphasizes the differences between direct and indirect voting for a presidential candidate by showing how the electoral college system places different weights on the preferences of swing voters, depending on their location. The propositions show analytically that incremental distributional changes between states that alter the distribution of leads within states can have a significant effect on the incentives for policy implementation.

The propositions show that concentrations of swing voters with a particular trade policy stance have a larger impact on electoral outcomes when located in swing states. Moreover, their overall impact on the re-election probability of incumbents increases if their influence is spread over swing states that constitute a larger proportion of electoral college votes and are thus more decisive for the election.

The propositions thus combine to give the overall prediction that the trade policy preferences of a measure of swing voters are more likely to be satisfied if these swing voters are concentrated in states that are both swing and decisive for the election outcome. Since voters with strong views over the protection of a particular industry are likely to be stakeholders in that industry, whether employees, entrepreneurs, shareholders etc., the main testable empirical implication of the model is that industries that are concentrated in swing and decisive states are more likely to be protected. The next section describes the results of our empirical investigation using US data that tests for the empirical implication of the model.

\section{Empirical Analysis}

This section provides evidence supporting the theoretical prediction that industries with large concentrations in swing and decisive states are more likely to be protected. The empirical analysis employs a benchmark test of the "Protection for Sale" mechanism of Grossman and Helpman (1994) using the empirical 
model and data of Gawande and Bandyopadhyay (2000). This baseline constitutes the "state-of-the-art" in empirical political economy of trade. We augment it with the data necessary to test our hypothesis that industrial concentration in key political districts is a significant determinant of trade policy. While the empirical specification does not form a direct test of our model, we present reduced form evidence that suggests previous empirical studies of the Grossman and Helpman (1994) model have omitted variables from their analysis that our theoretical analysis puts forward as being relevant.

The rest of the section proceeds as follows. First we outline the model and data of Gawande and Bandyopadhyay (2000). Second, we present the data and method of construction for the measure used to capture the swingness and decisiveness elements of the model. Finally, our results are described.

\subsection{Data and Empirical Specification}

The theoretical model developed in section 2 considers how electoral incentives influence a binary trade policy decision that reflects either free trade or trade protection. The precise nature of this trade protection instrument is unspecified in the model, but is distinguished by the discretion the political incumbent is assumed to have over it.

In practice, unilateral political discretion over trade policy, in particular import tariffs, is constrained by multilateral agreements. Import tariffs are thus jointly determined through multilateral trade negotiations rather than the sole result of a government's political agenda. Moreover, tariff levels for manufacturing products are very low since they have been greatly reduced over last few decades under the GATT and WTO. In contrast, Non-Tariff Barriers (NTBs) allow governments to exercise more discretion in trade protection since these are not regulated to the extent of tariffs. For this reason, the literature has mainly employed coverage ratios for non-tariff barriers as a measure of trade protection, where these represent the share of products within an industry that benefit from one or more quantitative or qualitative trade restrictions: quantityoriented barriers such as voluntary export restraints and quotas, price-oriented measures such as antidumping and countervailing duties, and threats of quantity and quality monitoring. We therefore adopt the same approach as in the related literature ${ }^{12}$ in considering NTB coverage ratios as our measure of trade protection. Data on Non-Tariff Barriers for $1983^{13}$ has been collected by the $\mathrm{UNCTAD}^{14}$ and combined with data from World Bank tapes ${ }^{15}$.

The benchmark specification by Gawande and Bandyopadhyay (2000) tests the original "Protection for Sale" equation of Grossman and Helpman (1994),

\footnotetext{
${ }^{12}$ Leamer (1990) details the construction of NTB coverage ratios. These have been widely used, for example, in Leamer (1990), Trefler (1993), Gawande (1998), Lee and Swagel (1997), Goldberg and Maggi (1997), Gawande and Bandyopadhyay (2000) and Bombardini (2005).

${ }^{13}$ Since 1983 is the only year for which NTB data is available, it is not possible to test the term limit effects predicted by the model.

${ }^{14}$ UNCTAD: United Nations Conference on Trade and Development.

${ }^{15}$ This dataset has been kindly provided by Kishore Gawande.
} 
reproduced in (28), where $t_{i}$ denotes the protection of industry $i, z_{i}$ is the inverse of the import penetration ratio, $e_{i}$ is the price elasticity of imports and $I_{i}$ describes whether sector $i$ is politically organised and represented by a lobby. Further, $\alpha_{L}$ represents the proportion of the population that is organised and $\alpha$ denotes the weight of contributions to the linear welfare function of the government.

$$
\frac{t_{i}}{1+t_{i}}=\frac{I_{i}-\alpha_{L}}{\alpha+\alpha_{L}} \frac{z_{i}}{e_{i}}
$$

Gawande and Bandyopadhyay (2000) demonstrate that lobbying competition and lobbying spending have an influence on protection in the US by estimating a system of three equations, of which only one is relevant to this analysis. This equation is reproduced in (29), where $t_{i}$ is the coverage ratio for industry $i, z_{i}$ is the inverse of the import penetration ratio, the share of imports to total production in sector $i, e_{i}$ is the price elasticity of imports and $I_{i}$ is a dummy variable that describes whether the sector is politically organised and represented by a lobby. Moreover, $Z_{1 i}$ includes tariffs on intermediate goods and $Z_{2 i}$ includes NTBs on intermediate goods as controls. The error term is denoted by $s_{i}$.

$$
\frac{t_{i}}{1+t_{i}}=\gamma_{0}+\gamma_{1} I_{i} \frac{z_{i}}{e_{i}}+\gamma_{2} \frac{z_{i}}{e_{i}}+Z_{1 i}+Z_{2 i}+s_{i}
$$

A simultaneity problem was raised by Trefler (1993). Higher trade protection is likely to reduce import penetration, as reflected in the following equation, in which $\varepsilon_{i}$ is the error term ${ }^{16}$.

$$
\frac{1}{z_{i}}=\phi \frac{t_{i}}{1+t_{i}}+\varepsilon_{i}
$$

Import penetration and trade protection are therefore determined simultaneously. In order to correct for the simultaneity bias implied by the system of equations (29) and (30), an instrumental variables approach is adopted. The capital-labour ratio interacted with industry dummies and comparative advantage variables (fractions of managers, scientists and unskilled labour per industry) are used as instruments, as in Trefler (1993). A complete list of the instruments used is reported in Appendix D. As in Gawande and Bandyopadhyay (2000), we use a two-stage least-squares estimator, and include for each of the instruments a linear term, a squared term, and the interactions of the linear term with, $e_{i}$, the price elasticity of imports.

The data used for import penetration ratios for the US are identical to those used by Trefler (1993). Considered as the most accurate estimate of sectorlevel price elasticity of imports, the data was taken originally from Shiells et al. (1986). The dummy variable, $I_{i}$, indicates whether a sector is politically

\footnotetext{
${ }^{16}$ Note that coefficient $\phi$ is not the same character employed in the theoretical section.
} 
organised and is constructed by Gawande and Bandyopadhyay (2000) based on US data from the Federal Election Commission ${ }^{17}$.

\subsection{Measuring Concentration}

To test the hypothesis that sectors whose activity is concentrated in US states with strong electoral competition ('swingness') and with the electoral votes to influence electoral outcomes ('decisiveness') are more likely to be protected, we require a measure to capture this form of geopolitical concentration. We therefore construct a measure of this concentration by combining two datasets. The first dataset allows us to construct the geographical concentration of industries across US states, based on employment. We use the 1987 Standard Industrial Classification (SIC) data from the Bureau of Labor Statistics (BLS) Quarterly Census of Employment and Wages (QCEW) for the year 1983, which gives us state-level employment at the four digit SIC.

The second dataset measures the swingness and decisiveness of electoral states in the presidential election ${ }^{18}$ of 1984 . Strömberg (2005) develops a probabilistic voting approach to presidential election campaigns and estimates an approximate measure $Q_{s}$ of the joint probability of a state $s$ being both decisive in the Electoral College and a swing state with a very close state-level election. It therefore encompasses the two factors put forward by Propositions (4) and (5) as being important in determining trade policy. He shows how measure $Q_{s}$ depends on several factors, such as the variance of national popularity-swings or the variance of electoral vote distribution, which could be interpreted as the state level and aggregate level uncertainties in the model of Section 2.

The $Q$-values are estimated for each presidential election using national and state-level measures. We use measure $Q_{s}$, estimated by David Strömberg for the 1984 presidential election for each state, whose mean is 0.02 and that ranges between a value close to zero and 0.07. The probability of being swing and decisive is never 0 or 1 , reflecting, as in our model, that no state is expected to be won with certainty. The NTBs in place in 1983 would, according to our model, be related to the expected swingness and decisiveness for the forthcoming election. This is exactly what the $Q_{s}^{1984}$ measure. At the national level, the Democrat proportion of the two-party vote share in trial-heat polls, economic growth, incumbency and incumbent president running for re-election are used. Moreover, at the state level, the difference from the national mean of the Democrat proportion of the two-party vote share in the 1980 election, the average ADA-scores ${ }^{19}$ of each state's Congress members the year prior to the election and the difference between state and national polls are included.

The well-established $Q_{s}$ measure of Strömberg (2005) constitutes a convenient measure for the reduced form specification as it combines the 'swingness'

\footnotetext{
${ }^{17}$ Gawande and Bandyopadhyay (2000) give a detailed desription of the derivation of this dummy.

${ }^{18}$ This data was kindly provided by David Strömberg.

${ }^{19}$ ADA (Americans for Democratic Action) scores, ranging from 0 to 100, are used as a measure of legislator ideology.
} 
of states, reflecting the electoral competitiveness, with 'decisiveness', reflecting the size of states and the necessity of winning a certain number of states to win the overall election. To check the suitability of this measure, we calculate the correlation between the $Q_{s}$ for the 1984 presidential election and a stateindustry Herfindahl index in 1983. This is found to be -0.4 (significant at the $1 \%$ level), showing that industrial concentration is not directly correlated with the probability of being swing and decisive.

Since the political data, encapsulated by measure $Q_{s}$, is constructed at the state level, while trade protection is measured at the industry level, we use the BLS dataset to link the two dimensions by creating an industry-specific measure of swingness and decisiveness, $q_{i}$. Besides being necessary for the empirical analysis, it also corresponds to the assumption of our model that employees of a sector in a state are protectionist swing voters in that state. In order to abstract from any size effects, we measure the state specialisation of each industry as the deviation in each state from its mean share of national employment. We can then compute a 4 -digit $\mathrm{SIC}$ ' $Q_{s}$ ' measure, denoted by $q_{i}$ using:

$$
q_{i}=1000 \times \sum_{s=1}^{S}\left[Q_{s} \times\left(\frac{L_{i s}}{L_{s}}-\frac{L_{i}}{L}\right)\right]
$$

where $i \in I$ denotes each of the 242 4-digit SIC industries used by Gawande and Bandyopadhyay (2000) and $s \in S$ denotes each of the 48 continental states $^{20}$. Total US employment is represented by $L$, while aggregate industry and state employment are respectively $L_{i}$ and $L_{s}$. Industries that constitute a higher proportion of a state's employment than their proportion of national employment, for a given $Q_{s}$, have a higher $q_{i}$. Conversely, if an industry constitutes a lower proportion of a state's employment than it does of national employment, then $q_{i}$ is lower. Moreover, for a given proportion of a state's employment, if the state has a low joint probability of being both swing and decisive, then $q_{i}$ is low. Taking the deviation from the mean rather than a pure state level measure of concentration allows to abstract from the possibility that nationally important industries will be important in all states. The sum is multiplied by 1000 as multiplying the probability $Q_{s}$ by a share yields very small numbers.

Table (1) presents the descriptive statistics of this constructed measure, which show that $q_{i}$ varies widely across industries. This confirms that industrial concentration through space and in specific swing and decisive states is not uniform. We check that our results are robust to excluding outlying observations of $q_{i}$. The correlations with other industry characteristics are reported in the third column of the table. Total employment, labour and skill intensity are not correlated with $q_{i}$, demonstrating that larger, or more skill or labour intensive industries do not systematically concentrate more in states that are more likely to be swing and decisive.

Augmenting the specification of Gawande and Bandyopadhyay (2000) to include the constructed industry level swingness and decisiveness variable, $q_{i}$, gives the following specification:

${ }^{20}$ Excluding the District of Columbia, Alaska, Hawai, Puerto Rico and the Virgin Islands. 
Table 1: Descriptive statistics of qi

\begin{tabular}{c|c|c}
\multicolumn{2}{c|}{ Descriptive statistics of $\mathrm{q}_{\mathrm{i}}$} & Correlation of $\mathrm{q}_{\mathrm{i}}$ with \\
\hline \hline Mean & Min & Labour intensity \\
0.07 & -0.49 & 0.14 \\
Median & Max & Proportion of unskilled workers \\
0.03 & 1.45 & -0.04 \\
sd & Range & Total employment \\
0.17 & 1.94 & 0.49 \\
\hline
\end{tabular}

Notes: Industry- specific measure of swingness and decisiveness, qi, computed from data for 242 four-digit SIC industries using Stromberg's (2005) measure of the probability of being swing and decisive and the Bureau of Labour Statistics employment dataset. Summary statistics are provided in the first two columns of the table. The third column reports the correlation of the measure with three other industry characteristics: Labour intensity, as the fraction of payroll in value added in 1982, Proportion of unskilled workers as the share of employees in an industry classified as unskilled in 1982, and total employment measured in millions of persons for 1982. Source: BLS (1983), 1982 Census of Manufacturing, Stromberg (2005).

$$
\frac{t_{i}}{1+t_{i}}=\gamma_{0}+\gamma_{1} I_{i} \frac{z_{i}}{e_{i}}+\gamma_{2} \frac{z_{i}}{e_{i}}+\gamma_{3} q_{i}+Z_{1 i}+Z_{2 i}+s_{i}
$$

which is also corrected for the simultaneity bias by using IV. The campaign contributions literature does not suggest the concentration of industries in swing and decisive states as a determinant for trade policy decision-making, implying that $\gamma_{3}$ is zero. The next section provides evidence that $q_{i}$ is a significant determinant of NTB protection of an industry, thus lending support to our theoretical results.

\subsection{Empirical Results}

Our findings are reported in table (2). The first column reports the results of the benchmark specification given by (29). It is consistent with the coefficients reported ${ }^{21}$ in Gawande and Bandyopadhyay (2000) and qualitatively close to those obtained by Goldberg and Maggi (1999). As predicted by Grossman and Helpman (1995), in politically organised sectors, higher industry output relative to imports and a lower price elasticity of imports increases the level of protection

\footnotetext{
${ }^{21}$ The significance levels of the coefficients are smaller than those reported in their paper due to our use of robust standard errors.
} 
Table 2: Reduced form regression results

\begin{tabular}{|c|c|c|c|c|}
\hline \multirow[t]{3}{*}{ Dependent Variable: } & \multicolumn{4}{|c|}{$\mathrm{NTB}_{\mathrm{i}} /\left(1+\mathrm{NTB}_{\mathrm{i}}\right)$} \\
\hline & \multicolumn{2}{|c|}{ (1) } & \multicolumn{2}{|c|}{ (2) } \\
\hline & & Beta & & Beta \\
\hline $\mathrm{q}_{\mathrm{i}}$ & & & $\begin{array}{c}0.192^{* *} \\
(0.038)\end{array}$ & 0.233 \\
\hline $\mathrm{I}_{\mathrm{i}}\left(\mathrm{z}_{\mathrm{i}} / \mathrm{e}_{\mathrm{i}}\right)$ & $\begin{array}{l}4.761^{+} \\
(2.781)\end{array}$ & 1.383 & $\begin{array}{c}3.330 \\
(2.532)\end{array}$ & 0.967 \\
\hline $\mathrm{z}_{\mathrm{i}} / \mathrm{e}_{\mathrm{i}}$ & $\begin{array}{c}-4.704^{+} \\
(2.664)\end{array}$ & -1.384 & $\begin{array}{l}-3.319 \\
(2.402)\end{array}$ & -0.977 \\
\hline Intermediates' tariffs & $\begin{array}{l}0.734^{*} \\
(0.319)\end{array}$ & 0.190 & $\begin{array}{c}0.809 * * \\
(0.312)\end{array}$ & 0.209 \\
\hline Intermediates' NTBs & $\begin{array}{c}0.378^{* *} \\
(0.090)\end{array}$ & 0.388 & $\begin{array}{c}0.337 * * \\
(0.086)\end{array}$ & 0.345 \\
\hline Observations & 242 & 242 & 242 & 242 \\
\hline F-test model (p-value) & 0.00 & 0.00 & 0.00 & 0.00 \\
\hline J-test overidentification ( $\mathrm{p}$-value) & 0.04 & 0.04 & 0.08 & 0.08 \\
\hline Centered $\mathrm{R}^{2}$ & 0.21 & 0.20 & 0.29 & 0.28 \\
\hline Estimator & 2SLS & & 2SLS & \\
\hline
\end{tabular}

Notes: IV-2SLS regressions, instruments reported in appendix D. Robust standard errors in parentheses; + denotes statistical significance at the $10 \%$ level; * denotes statistical significance at the $5 \%$ level; ** denotes statistical significance at the $1 \%$ level. Includes constant not reported. The dependent variable is the Non Tariff Barriers coverage ratio. In both specifications, $\left(\mathrm{z}_{\mathrm{i}} / \mathrm{e}_{\mathrm{i}}\right)$ is the ratio of inverse import penetration to import elasticity. $\mathrm{I}_{\mathrm{i}}\left(\mathrm{z}_{\mathrm{i}} / \mathrm{e}_{\mathrm{i}}\right)$ is the same ratio multiplied by a dummy $\mathrm{I}_{\mathrm{i}}$ that indicates whether a sector is politically organized or not. Intermediates tariff is computed as the average tariff on intermediate goods used by industry $i$ and Intermediates Ntbs the average Non Tariff Barriers coverage of these intermediates. In the second specification, an additional explanatory variable is added. Industry- specific measure of swingness and decisiveness, qi, computed from data for 242 four-digit SIC industries using Strömberg (2005) measure of the probability of being swing and decisive and the Bureau of Labor Statistics employment dataset. The beta coefficients are reported for both specifications. The p-values of the F-test model and J-test overidentification are reported. Data source: Gawande and Bandyopadhyay (2000), Strömberg (2005), BLS (1983) and authors' own calculations.

$\left(\gamma_{1}>0\right)$. In politically disorganised sectors, the coefficient has the opposite sign $\left(\gamma_{2}<0\right)$.

The results from specification (32) appear in column (2). Our measure of "industry swingness and decisiveness" does not affect the sign, magnitude of the coefficients on $I_{i}\left(z_{i} / e_{i}\right)$ and $z_{i} / e_{i}$. Their significance is only slightly reduced, indicating a relative robustness of the Grossman Helpman model. The point estimate of $\gamma_{3}$ is 0.192 (significant at the $1 \%$, with a robust standard error of 0.038). Thus sectors that concentrate more than their national average in swing and decisive states receive more protection. This estimate translates into a normalised beta coefficient of 0.233 , such that a one standard deviation increase in the industry's swingness and decisiveness will increase the US NTB coverage ratio for that sector by approximately 0.233 standard deviations. Although this beta is smaller than that of the Grossman-Helpman variables, it is more significant, and as important as the trade protection measures on intermediates. Moreover, including our measure of swingness and decisiveness explains a larger 
proportion of the variation of protection levels across sectors, as it increases the centered $R^{2}$ by $30 \%$ relative to the Gawande and Bandyopadhyay (2000) benchmark specification.

These findings provide supporting evidence for the hypothesis that industrial concentration in swing and decisive states is an important determinant of trade protection of that industry, highlighting geographical concentration of industries in politically key states an important, and previously overlooked, determinant of trade protection in the US Electoral College.

\section{Conclusion}

The political agency model developed in this paper offers a multi-jurisdictional framework for analysing electoral incentives for trade protection. For distributions of voters where support by swing voters increases re-election probability, a unique equilibrium is shown to exist where political incumbents build a reputation of protectionism through their policy decisions in their first term of office. The extension to a multi-state framework modelled as an electoral college introduces a spatial dimension that shows how the incentives driving trade policy hinge on the distribution of swing voters across swing states. We show that strategic trade protection is more likely when protectionist swing voters have a lead over free-trade supporters in states with relatively strong electoral competition, swing states, that also represent a larger proportion of electoral votes, thus being more decisive in the overall election. The analytical results offer a theoretical explanation for why governments may sometimes push for the protection of industries with concentrations in pivotal locations, such as the US steel production industry. Moreover, our empirical strategy augments the benchmark test of the lobbying political economy of trade literature to include a measure of how industries specialise geographically in these swing and decisive states. The reduced form evidence is that the concentration of industries in politically important states is a significant element in explaining trade policy. These findings provide support for the theory highlighting an important, and previously overlooked, determinant of trade protection.

\section{References}

[1] Baldwin, R. (1985), The Political Economy of U.S. Import Policy, Cambridge, MA: MIT Press

[2] Barro, R.(1973), "The Control of Politicians: An Economic Model", Public Choice, Vol.14, No. 1, pp. 19-42

[3] Besley, T. and R. Burgess (2002), "The Political Economy of Government Responsiveness: Theory and Evidence from India", Quarterly Journal of Economics, Vol.117, No.4, pp. 1415 -1451 
[4] Besley, T. and A. Case (1995), "Does Electoral Accountability Affect Economic Policy Choices? Evidence From Gubernatorial Term Limits", Quarterly Journal of Economics, Vol. 60, No. 3, pp. 769-798

[5] Bombardini, M. (2005), "Firm Heterogeneity and Lobby Participation", University of British Columbia, mimeo

[6] Bureau of Labor Statistics, Quarterly Census of Employment and Wages, http://www.bls.gov/cew/home.htm, 1983

[7] Busch, M. and E. Reinhart (1999), "Industrial Protection and Location, The Political and Economic Geography of U.S. Nontariff Barriers", American Journal of Political Science, Vol. 43, No. 4, pp. 1028-1050

[8] Caves, R. (1976), "Economic Models of Political Choice: Canada's Tariff Structure", Canadian Journal of Economics, Vol. 9, No. 2, pp. 278-300

[9] Coate, S. and S. Morris, (1995), "On the Form of Transfers to Special Interests", Journal of Political Economy, Vol.103, No. 6, pp. 1210 - 1235

[10] Cox, G. W. and Munger, M. C. (1989), "Closeness and Turnout: a Methodological Note", The Journal of Politics, Vol. 50, No. 3, pp. 768-775

[11] Corden, W (1974), Trade Policy and Welfare, Oxford: Oxford University Press

[12] Eicher, T. and T. Osang (2002) "Protection for Sale: An Empirical Investigation: A Comment", American Economic Review, Vol. 92, No. 5, pp.1702-1711

[13] Gawande, K. (1998), "Comparing Theories of Endogenous Protection: Bayesian Comparison of Tobit Models Using Gibbs Sampling Output", Review of Economics and Statistics, Vol. 80, No. 1, pp. 128-140

[14] Gawande, K. and U. Bandyopadhyay (2002), "Is Protection for Sale? Evidence on the Grossman-Helpman Theory of Endogenous Protection", Review of Economics and Statistics, Vol. 82, No. 1, pp. 139-152

[15] Geys, B. (2006), "Explaining Voter Turnout: a Review of Aggregate-Level Research", Electoral Studies, Vol. 25, No.4, pp. 637-663

[16] Goldberg, P. K. and G. Maggi (1999), "Protection for Sale: An Empirical Investigation", American Economic Review, Vol. 89 , No. 5, pp.1135-1155

[17] Grossman, G. and E. Helpman (1994), "Protection for Sale", American Economic Review, Vol. 84, No. 4, pp. 833-850

[18] Grossman, G. and E. Helpman (1996), "Electoral Competition and Special Interest Politics", Review of Economic Studies, Vol.63, No. 2, pp. 265-286 
[19] Grossman, G. and E. Helpman (2001), Special Interest Politics, Cambridge, The MIT Press

[20] Grossman, G. and E. Helpman (2002), Interest Groups and Trade Policy, Princeton, Princeton University Press

[21] Hansen, W. L. (1990), "The International Trade Commission and The Politics of Protectionism", American Political Science Review, Vol. 84, No. 1, pp. 21-46

[22] Helpman, E.(1997), "Politics and Trade Policy", in Advances in Economics and Econometrics: Theory and Applications, David Kreps and Kenneth Wallis (eds.), Cambridge, MA: Cambridge University Press

[23] Leamer, E.(1990), "The Structure and Effects of Tariff and Nontariff Barriers in 1983", in R.W. Jones and A. Krueger (eds.), The Political Economy of International Trade: Essays in Honor of Robert E. Baldwin, Cambridge, MA: Basil Blackwell

[24] Lee, J-W. and P. Swagel (1997), "Trade Barriers and Trade Flows Across Countries and Industries", Review of Economics and Statistics, Vol. 79, No. 3, pp. $372-382$

[25] List, J. and D. Sturm (2006), "How Elections Matter: Theory and Evidence from Environmental Policy", The Quarterly Journal of Economics, Vol. 121, No. 4, pp. 1249-1281

[26] Matsusaka, J. G. (1993), "Election Closeness and Voter Turnout: Evidence from California Ballot Propositions", Public Choice, Vol. 76, No. 4 pp.313334

[27] Mayer, W. (1984), "Endogenous Tariff Formation", American Economic Review, Vol. 74, No. 5, pp. 970-985

[28] Mitra, D. (1999), "Endogenous Lobby Formation and Endogenous Protection: A Long-Run Model of Trade Policy Determination", American Economic Review, Vol. 89, No. 5, pp. 1116-1134

[29] Olson, M. (1971), The Logic of Collective Action: Public goods and the theory of groups, Cambridge, MA: Harvard University Press

[30] Pincus, J. (1975), "Pressure Groups and the Pattern of Tariffs", Journal of Political Economy, Vol. 83, No. 4, pp. 757-778

[31] Roelfsema, H. (2004), "Political Institutions and Trade Protection", Utrecht School of Economics, Discussion Paper Series nr: 04-06

[32] Shiells, C. R, R. M. Stern and A. V. Deardorff (1986), "Estimates of the Elasticities of Substitution between Imports and Home Goods for the United States," Weltwirtschaftliches Archiv, Vol. 122, No. 3, pp. 497-519 
[33] Strömberg, D. (2005), "How the Electoral College Influences Campaigns and Policy: The Probability of Being Florida", IIES, Stockholm University, mimeo

[34] Trefler, D.(1993), "Trade Liberalization and the Theory of Endogenous Protection: An Econometric Study of U.S. Import Policy," Journal of Political Economy, Vol. 101, No. 1, pp.138-160

[35] Wiberg, M. (2005), "Endogenous Tariff Formation and the Political Economic of Retaliation, Liberalization and Trade Wars under Representative Democracy", Stockholm University, mimeo

[36] Willmann, G.(2003), "Why Legislators are Protectionists: the Role of Majoritarian Voting in Setting Tariffs", Kiel Working Paper 2003-10

[37] Yang, C. (1995), "Endogenous Tariff Formation under Representative Democracy: A Probabilistic Voting Model", American Economic Review, Vol.85, No. 4, pp.956-963 


\section{Appendix A. Voter Value Functions}

Section 2 establishes the optimality of the incumbents' strategies, given voters' strategies, for the equilibrium where $\Delta v>0$. This appendix shows that the reelection rule of the infinitely-lived $F$ and $P$ swing voters is also optimal, given politicians' strategies. This confirms that the politicians' and voters' strategies constitute a Markov Perfect equilibrium of the game.

Let $V_{P}$ denote the value function for a protectionist voter. Further, let $\sigma_{P}^{r}$ denote the probability that a $P$ voter votes for the incumbent, given policy $r$ in his first term of office. $\sigma_{P}^{r}$ contributes to the incumbent's re-election probability by a tiny amount, thus marginally affecting his prospective payoffs. $\sigma_{P}^{r}$ is thus introduced in $V_{P}$ as an argument of the incumbent's re-election probability, $f(\cdot)$, which is smooth and continuous from the assumptions of the model. Further, let $u_{P}^{1}(\pi)$ denote the utility of $P$ voters in the incumbent's first term of office, where $\pi$ is the probability of the incumbent having protectionist views. Similarly, denote $P$ voters' second term utility as $u_{P}^{2}\left(\widetilde{\pi}^{r}\right)$, where this is a function of update beliefs after observing $r$ in the first term. Finally, $\beta$ is the common discount factor. Combining these allows the value function, $V_{P}$, to be expressed as follows:

$$
V_{P}=u_{P}^{1}(\pi)+\beta \sum_{r}\left[f\left(\sigma_{P}^{r}\right)\left(u_{P}^{2}\left(\widetilde{\pi}^{r}\right)+\beta V_{P}\right)+\left(1-f\left(\sigma_{P}^{r}\right)\right) V_{P}\right]
$$

The following proof uses (33) to show that given incumbents' strategies, $\sigma_{P}^{0}=0$ and $\sigma_{P}^{1}=1$ are optimal responses. That is, protectionists vote for the incumbent if he chooses trade protection in his first term and for the challenger if free trade is chosen. In order for $\sigma_{P}^{r}=1$ to be an optimal response, it must be true from (33) that $u_{P}^{2}\left(\tilde{\pi}^{r}\right)+\beta V_{P} \geq V_{P}$. This can be rearranged to the following condition:

$$
u_{P}^{2}\left(\widetilde{\pi}^{r}\right) \geq(1-\beta) V_{P}
$$

To see this, consider that $f\left(\sigma_{P}^{r}\right)$ and $1-f\left(\sigma_{P}^{r}\right)$ are weights for $u_{P}^{2}\left(\widetilde{\pi}^{r}\right)+\beta V_{P}$ and $V_{P}$, respectively, in the value function. Voter $P$ maximises his effect on $f\left(\sigma_{P}^{r}\right)$ through $\sigma_{P}^{r}=1$, and thus places the largest possible weight on $u_{P}^{2}\left(\tilde{\pi}^{r}\right)+$ $\beta V_{P}$ relative to $V_{P}$. Hence, $\sigma_{P}^{r}=1$ can only be optimal if (34) holds.

Recall that $P$ voters receive a payoff $x$ if $r=1$ and 0 otherwise. Since $\operatorname{Pr}\left(r=1\right.$ in $1^{\text {st }}$ term $)=\pi+(1-\pi) p$, it follows that $u_{P}^{1}(\pi)=[\pi+(1-\pi) p] x>0$. Moreover, since $\operatorname{Pr}\left(r=1\right.$ in $2^{\text {nd }}$ term $\mid r=0$ in $1^{\text {st }}$ term $)=0$, it follows that $u_{P}^{2}\left(\tilde{\pi}^{0}\right)=0$. That is, the incumbent reveals himself to be a free-trader if he chooses $r=0$ in his first term, given $\Delta v>0$. Since the incumbent follows his preferences in his final term in office, so $P$ voters can be certain of a 0 payoff. If the incumbent sets $r=1$ in his first term, then voters can update their beliefs regarding the probability of $r=1$ being chosen in his second term, if re-elected. Applying Bayes' rule for $\tilde{\pi}^{1}, P$ voters can expect $u_{P}^{2}\left(\tilde{\pi}^{1}\right)=\frac{\pi x}{\pi+(1-\pi) p}$.

It must be true that $V_{P} \geq \frac{1}{1-\beta} u_{P}^{1}(\pi)$, where $\frac{1}{1-\beta} u_{P}^{1}(\pi)$ is the discounted 
stream of period 1 utilities, if the incumbent is never re-elected. Substituting into (34) yields:

$$
u_{P}^{2}\left(\widetilde{\pi}^{r}\right) \geq u_{P}^{1}(\pi)
$$

This must hold for $\sigma_{P}^{r}=1$ to be optimal, for all $r$, but leads to a contradiction. It cannot be true that $u_{P}^{2}\left(\widetilde{\pi}^{0}\right) \geq u_{P}^{1}(\pi)$ since $u_{P}^{2}\left(\widetilde{\pi}^{0}\right)=0$ and $u_{P}^{1}(\pi)>0$. Hence, $\sigma_{P}^{r}=1$ (for all $r$ ) cannot be an optimal response. Since $u_{P}^{2}\left(\widetilde{\pi}^{0}\right)<u_{P}^{1}(\pi)$, a new politician is always a better bet than an incumbent who set $r=0$ in his first term. Hence, $\sigma_{P}^{0}=0$ is optimal. Moreover, continuation payoff $\frac{1}{1-\beta} u_{P}^{1}(\pi)$ must be smaller than $\frac{1}{1-\beta} u_{P}^{2}\left(\tilde{\pi}^{1}\right)$ under the equilibrium strategies of incumbents', so $\sigma_{P}^{1}=1$ is an optimal response.

The value function of free-traders, $V_{F}$, is symmetric to $V_{P}$ and the optimality strategies $\sigma_{F}^{0}=1$ and $\sigma_{F}^{1}=0$ follows with arguments symmetric to those used above. We can thus conclude that the politicians' and voters' strategies constitute a Markov Perfect equilibrium of the game.

\section{Appendix B. Equilibrium Uniqueness}

There are two symmetric cases, $\Delta v>0$ and $\Delta v<0$, where reputation-building through strategic policy implementation forms part of incumbents' optimal strategies. In each of these symmetric cases, there is a unique equilibrium. To show that the equilibrium found in the paper is unique, consider a distribution of swing voters under which $\Delta v>0$ from the implementation of trade protection in the first term.

Recall that when a high $\operatorname{cost} c_{H}$ is drawn, it is a dominant strategy for freetrader politicians to set $r=1$. Moreover, let $\sigma_{P}^{r}$ denote the probability that a $P$ voter votes for the incumbent, given policy $r$ in his first term of office. Under a sufficiently low cost draw, $c_{L}$, it must be the case that $\sigma_{P}^{1}>\sigma_{P}^{0}$ for a free-trader to deviate from $r=0$. Similarly, for a protectionist to deviate from $r=1$ in his first term of office, it must be true that $\sigma_{P}^{1}<\sigma_{P}^{0}$. Hence, in any equilibrium at most one type of politician deviates from his preferred policy in the first term.

Moreover, to show that mixing between $r=0$ and $r=1$ cannot be an equilibrium, consider a strategy where a free-trader incumbent sets $r=1$ with a probability less than 1 when $c=c_{L}$. For this to be an equilibrium, it must be the case that $\sigma_{P}^{1} \beta \zeta-c_{L}=\sigma_{P}^{0} \beta \zeta$ and hence that $c_{L}=\left(\sigma_{P}^{1}-\sigma_{P}^{0}\right) \beta \zeta$. Inspection of $V_{P}$ in Appendix A shows that $\sigma_{P}^{1}=1$ and $\sigma_{P}^{0}=0$ remain optimal. This, however, implies that $c_{L}=\beta \zeta$ that contradicts the assumption that $\beta \zeta>c_{L}$.

It can similarly be shown that a strategy in which a protectionist sets $r=1$ with less than certainty can never form part of an equilibrium. Such a strategy requires that $\sigma_{P}^{1} \beta \zeta=\sigma_{P}^{0} \beta \zeta-c_{L}$, that implies $c_{L}=\left(\sigma_{P}^{0}-\sigma_{P}^{1}\right) \beta \zeta$. This is impossible, however, since voters' optimal strategy in this case is to set $\sigma_{P}^{1}=$ 1 and $\sigma_{P}^{0}=0$. It follows that the unique equilibrium outcome is for an $F$ incumbent to set $r=1$ when $c=c_{L}$ and for a $P$ incumbent to also set $r=1$ under a low cost draw. 
We can conclude that the equilibrium discussed in the paper is unique for distributions of swing voters that satisfy the conditions for this case, and sufficiently low $p$ and $c_{L}$. Symmetric arguments apply for the alternative case where $\Delta v<0$.

\section{Appendix C. Untested Candidates}

Consider an election taking place between two randomly selected candidates, each with a probability $\pi$ of being protectionist. Since neither candidate has a history of a trade policy decision on which swing voters can condition their voting decision, the swing voters cast their vote on the basis of a coin toss. Each candidate can thus expect to gain $\frac{1}{2}\left(\gamma_{P}^{s}+\gamma_{F}^{s}\right)$. Hence, the Democrat candidate gains $\gamma_{D}^{s}+\frac{1}{2}\left(\gamma_{P}^{s}+\gamma_{F}^{s}\right)+\nu^{s}$ and the Republican candidate gains $\gamma_{R}^{s}+\frac{1}{2}\left(\gamma_{P}^{s}+\gamma_{F}^{s}\right)-\nu^{s}$. For the $D$ candidate to win a majority in state $s$, $2 \nu^{s}=\varepsilon^{s}$ must exceed $\gamma_{R}^{s}-\gamma_{D}^{s}=-\omega_{p}^{s}$. Let $\rho^{s}$ denote the probability that the $D$ candidate wins a majority in state $s$. It follows from the distribution of $\varepsilon^{s}$ that:

$$
\begin{aligned}
\rho^{s} & =\operatorname{Pr}\left(\varepsilon^{s}>-\omega_{p}^{s}\right)=1-H\left(-\omega_{p}^{s}\right) \\
& =H\left(\omega_{p}^{s}\right)
\end{aligned}
$$

Hence, $1-H\left(\omega_{p}^{s}\right)$ is the probability that $R$ wins majority in state $s$. Hence state-level outcomes depend only on the political lead in $s$ and $H\left(\varepsilon^{s}\right)$. This stems from the assumption that single-issue voters randomly select between the two candidates, so each candidate can expect to gain support by half. An alternative voting strategy could allocate swing voters in a different proportion. For example, when candidates are not distinguishable with regards to trade policy, voters may cast a vote on the basis of underlying ideological position, that is otherwise dominated by trade policy considerations. 


\section{Appendix D. Variables and Instruments}

The following table provide a descriptions of all the variables and instruments used in the empirical analysis of section 3 .

Table 3: Variables and instruments list

\begin{tabular}{|c|c|}
\hline Variable & Description \\
\hline $\begin{array}{l}\mathrm{NTB}_{\mathrm{i}} \\
\mathrm{q}_{\mathrm{i}}\end{array}$ & $\begin{array}{l}\text { Aggregate US Non Tariff Barriers coverage ratio across all partners for industry } i \\
\text { Constructed measure of the concentration of 4-digit SIC industry } i \text { in swing and decisive } \\
\text { political states }\end{array}$ \\
\hline $\mathrm{I}_{\mathrm{i}}$ & Dummy variable, value 1 when sector $i$ is politically organized \\
\hline $\mathrm{Z}_{\mathrm{i}}$ & $\begin{array}{l}\text { Inverse of import penetration ratio divided by } 10000 \text { (= (US consumption in } 1983 / \text { US } \\
\text { total imports)/10000) in sector } \mathrm{i}\end{array}$ \\
\hline & Price elasticity of imports in sector i, corrected for errors-in-variables (GB, 2000) \\
\hline Interm. tariffs & Average tariff on intermediate goods used in industry $\mathrm{i}$ \\
\hline Interm. NTBs & Average NTB coverage ratio on intermediate goods used in industry i \\
\hline \multicolumn{2}{|l|}{ Instrument } \\
\hline 1 & Average tariff on intermediate goods used in industry i \\
\hline 2 & Average NTB coverage ratio on intermediate goods used in industry $i$ \\
\hline 3 & Price elasticity of imports (1986) \\
\hline 4 & Logarithm of the price elasticity of imports $e_{i}$ \\
\hline 5 & Measure of the size of firms in an industry: Value added per firm, 1982, (\$Bn/firm) \\
\hline 6 & $\begin{array}{l}\text { Share of output in a sector produced by the four largest producers. concentration ratio, } \\
1982\end{array}$ \\
\hline 7 & Share of employees in the industry defined as scientistsand engineers, 1982 \\
\hline 8 & Share of employees in the industry defined as managerial, 1982 \\
\hline 9 & Share of employees in the industry defined as unskilled, 1982 \\
\hline 10 & Real Exchange Rate elasticity of imports \\
\hline 11 & $\begin{array}{l}\text { Cross price elasticity of imports with resepct to domestic prices, corrected for errors-in- } \\
\text { variables }(\mathrm{GB}, 2000)\end{array}$ \\
\hline 12 & Log percentage of an industry's output used as intermediate good in other sectors \\
\hline 13 & Logarithm of the intermediate goods buyer concentration \\
\hline 14 & Herfindahl index of the industry \\
\hline 15 & Ad valorem tariff \\
\hline 16 & Capital-Labor ratio of the industry x Dummy for food processing industry \\
\hline 17 & Capital-Labor ratio of the industry x Dummy for resource-intensive industry \\
\hline 18 & Capital-Labor ratio of the industry x Dummy for general manufacturing industry \\
\hline 19 & Capital-Labor ratio of the industry x Dummy for capital intensive industry \\
\hline $20-36$ & Instruments 3 to 19 squared \\
\hline $37-52$ & Instruments 4 to $19 \mathrm{x}$ price elasticity of imports $\mathrm{e}_{\mathrm{i}}$ \\
\hline
\end{tabular}




\section{CENTRE FOR ECONOMIC PERFORMANCE Recent Discussion Papers}

848 Dimitra Petropoulou

847 Bernardo Guimaraes

846 Javier Ortega

Laurence Rioux

845 Richard E. Baldwin

Frédéric Robert-Nicoud

844 Richard B. Freeman

843 Emma Hall

Carol Propper

John Van Reenen

842 Fabrice Defever

Farid Toubal

841 Barbara Petrongolo

840 Kevin D. Sheedy

839 Christopher A. Pissarides

838 Kevin D. Sheedy

837 Kevin D. Sheedy

836 Andrew E. Clark Ed Diener

Yannis Georgellis

Richard E. Lucas

835 Jean-Baptiste Michau

834 Nikolaus Wolf

833 Sharon Belenzon

Tomer Berkovitz
Information Costs, Networks and Intermediation in International Trade

Optimal External Debt and Default

On the Extent of Re-Entitlement Effects in Unemployment Compensation

A Simple Model of the Juggernaut Effect of Trade Liberalisation

Labor Market Institutions Around the World

Can Pay Regulation Kill? Panel Data Evidence on the Effect of Labor Markets on Hospital

Performance

Productivity and the Sourcing Modes of

Multinational Firms: Evidence from French FirmLevel Data

What are the Long-Term Effects of UI? Evidence from the UK JSA Reform

Robustly Optimal Monetary Policy

The Unemployment Volatility Puzzle: Is Wage Stickiness the Answer?

Inflation Persistence when Price Stickiness

Differs between Industries

Intrinsic Inflation Persistence

Lags and Leads in Life Satisfaction: A Test of the Baseline Hypothesis

Creative Destruction with On-the-Job Search

Scylla and Charybodis: the European Economy and Poland's Adherence to Gold, 1928-1936

Innovation in Business Groups 
832 Espen R. Moen
Åsa Rosén

831 Eran Yashiv

830 Laura Alfaro

Andrew Charlton

829 Richard Layard

David Clark

Martin Knapp

Guy Mayraz

828 Emma Tominey

827 Christos Genakos

Tommaso Valletti

826 Luis Garicano

Paul Heaton

825 Laura Alfaro

Andrew Charlton

824 Miklós Koren

Silvana Tenreyro

823 Régis Barnichon

822 Carlos Thomas

821 Giulia Faggio Kjell G. Salvanes John Van Reenen

820 Luis Araujo

Emanuel Ornelas

819 Régis Barnichon

818 Rachel Griffith Sokbae Lee John Van Reenen

817 Tsutomu Miyagawa YoungGak Kim
Incentives in Competitive Search Equilibrium

U.S. Labor Market Dynamics Revisited

Growth and the Quality of Foreign Direct

Investment: Is All FDI Equal?

Cost-Benefit Analysis of Psychological Therapy

Maternal Smoking During Pregnancy and Early Child Outcomes

Testing the "Waterbed" Effect in Mobile

Telephony

Information Technology, Organization, and Productivity in the Public Sector: Evidence from Police Departments

Intra-Industry Foreign Direct Investment

Technological Diversification

The Shimer Puzzle and the Correct Identification of Productivity Shocks

Search Frictions, Real Rigidities and Inflation Dynamics

The Evolution of Inequality in Productivity and Wages: Panel Data Evidence

Trust-Based Trade

Productivity, Aggregate Demand and Unemployment Fluctuations

Is Distance Dying at Last? Falling Home Bias in Fixed Effects Models of Patent Citations

Measuring Organization Capital in Japan: An

Empirical Assessment Using Firm-Level Data

The Centre for Economic Performance Publications Unit Tel 02079557673 Fax 02079557595 Email info@cep.lse.ac.uk Web site http://cep.lse.ac.uk 